Article

\title{
Framework for WASH Sector Data Improvements in Data-Poor Environments, Applied to Accra, Ghana
}

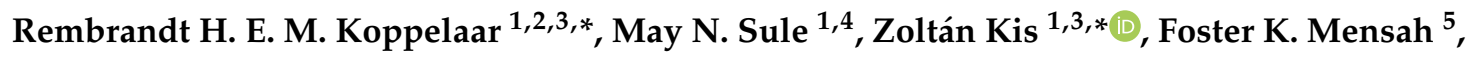 \\ Xiaonan Wang ${ }^{3,6}$, , Charalampos Triantafyllidis ${ }^{3,7}$, Koen H. van Dam ${ }^{3}\left(\mathbb{D}\right.$ and Nilay Shah ${ }^{3}$ \\ 1 Institute for Integrated Economic Research, The Broadway, London W5 2NR, UK; m.sule08@imperial.ac.uk \\ 2 Centre for Environmental Policy, Faculty of Natural Sciences, Imperial College London, South Kensington \\ Campus, London SW7 2AZ, UK \\ 3 Centre for Process Systems Engineering, Department of Chemical Engineering, Imperial College London, \\ South Kensington Campus, London SW7 2AZ, UK; chewxia@nus.edu.sg (X.W.); \\ charalampos.triantafyllidis@smithschool.ox.ac.uk (C.T.); k.van-dam@imperial.ac.uk (K.H.v.D.); \\ n.shah@imperial.ac.uk (N.S.) \\ 4 Department of Civil and Environmental Engineering, Faculty of Engineering, Imperial College London, \\ South Kensington Campus, London SW7 2AZ, UK \\ 5 Centre for Remote Sensing and Geographic Information Services, University of Ghana, Legon, Annie-Jiagge \\ Road, Accra, Ghana; fkmawusi@gmail.com \\ 6 Department of Chemical and Biomolecular Engineering, Faculty of Engineering, National University of \\ Singapore, 4 Engineering Drive 4, E5 03-04, Singapore 117585, Singapore \\ 7 Smith School of Enterprise and the Environment, School of Geography and the Environment, University of \\ Oxford, South Parks Road, Oxford OX1 3QY, UK \\ * Correspondence: rembrandtkoppelaar@protonmail.com (R.H.E.M.K.), z.kis10@imperial.ac.uk (Z.K.); \\ Tel.: +44-7843-121370 (R.H.E.M.K.)
}

Received: 12 August 2018; Accepted: 8 September 2018; Published: 18 September 2018

\begin{abstract}
Improvements in water, sanitation and hygiene (WASH) service provision are hampered by limited open data availability. This paper presents a data integration framework, collects the data and develops a material flow model, which aids data-based policy and infrastructure development for the WASH sector. This model provides a robust quantitative mapping of the complete anthropogenic WASH flow-cycle: from raw water intake to water use, wastewater and excreta generation, discharge and treatment. This approach integrates various available sources using a process-chain bottom-up engineering approach to improve the quality of WASH planning. The data integration framework and the modelling methodology are applied to the Greater Accra Metropolitan Area (GAMA), Ghana. The highest level of understanding of the GAMA WASH sector is achieved, promoting scenario testing for future WASH developments. The results show $96 \%$ of the population had access to improved safe water in 2010 if sachet and bottled water was included, but only $67 \%$ if excluded. Additionally, $66 \%$ of $338,000 \mathrm{~m}^{3}$ per day of generated wastewater is unsafely disposed locally, with $23 \%$ entering open drains, and $11 \%$ sewage pipes, indicating poor sanitation coverage. Total treated wastewater is $<0.5 \%$ in 2014 , with only $18 \%$ of $43,000 \mathrm{~m}^{3}$ per day treatment capacity operational. The combined data sets are made available to support research and sustainable development activities.
\end{abstract}

Keywords: anthropogenic WASH mapping; WASH planning tool; Accra WASH sector characterization; open data

\section{Introduction}

According to the $\mathrm{WHO}$ and UNICEF in 2015, 2.4 billion people (33\% of the global population) lacked access to improved sanitation facilities and 663 million people (9\% of the global population) 
lacked improved drinking water sources [1-3]. In developing countries, the proportion of people lacking access to improved sanitation and drinking water is substantially higher. For example, in Sub-Saharan Africa, $70 \%$ and 32\% of the population lacked improved sanitation and drinking water sources, respectively [1]. These deficiencies in the water, sanitation and hygiene (WASH) sector impose tremendous financial, health and environmental costs on developing countries and their inhabitants [4,5]. A key challenge for improving WASH insufficiencies in developing countries lays in the lack of data describing the local WASH situation, and consequently the inability for fact-based decision-making and policy implementation. This data poverty is often encountered in the form of data availability only at the aggregate level, with inadequate information available at the decentralised levels. Moreover, data may not be fully up-to-date. Other data quality issues include the scattered nature of datasets without temporal or spatial integration, and specifically for the WASH sector, lack of input-output integration from raw water to wastewater discharge. For example, for a review on urine and faeces excretion literature, please see Supplementary Material D. This results in the inability to tackle water leakage and evaluate designs of new water and sanitation systems tailored to the local context. Additionally, there is a need for an integrated and reliable resource-flow methodology that can provide a structured and objective process to characterize urban WASH sectors in developing countries [6,7]. Moreover, this methodology should also pinpoint key areas for improvements and identify optimal improvement strategies via scenario testing.

To overcome these challenges, we developed a framework for data integration and a robust and comprehensive bottom-up methodology for describing anthropogenic water and sanitation material flows, considering the complete cycle from raw water intake to water use, wastewater and excreta generation, to discharge and treatment. This approach allowed us to describe the current WASH status quo at a district level and to model and evaluate future scenarios (e.g., for infrastructure upgrading) to support decision makers. Additionally, progress on local water and sanitation targets as well as needs, infrastructure and system change can also be monitored using this framework.

The framework and descriptive modelling approach were applied to the Greater Accra Metropolitan Area (GAMA), the capital city region of Ghana. GAMA is a rapidly growing metropolitan region with 4 million inhabitants, where efforts to improve the WASH situation have yielded mixed results [8-10]. A limited number of recent studies jointly provide an overview of the water and sanitation situation and data availability in GAMA, including institutional stakeholder descriptions, and WASH financing analyses [11-16]. However, applicability for urban planning is, in this case, limited by the absence of an integration of various data sources to generate a comprehensive baseline assessment of urban water flows from raw water to wastewater treatment and discharge. Moreover, there is a need for a robust and comprehensive methodology for WASH flow-cycle mapping and WASH sector improvements via scenario testing. Therefore, GAMA was an ideal location for applying such a descriptive and decision-making aiding framework and modelling tool. The first objective of the case study was to fill this data integration gap by creating an integrated flow picture of water and sanitation in GAMA, via material flow analysis using raw data from existing studies, local publications and authorities. The second objective was to define a set of standardized metrics usable for further research, future updates, and scenario studies of improvements in GAMA water and sanitation flows, of which some can also be applied to urban water flow studies of other cities.

\section{Materials and Methods}

\subsection{Modelling Framework Development}

The study design is based on a literature data review and bottom-up material flow analysis approach. In a bottom-up approach, the individual base elements of the system are specified in detail and combined using first-principle physical and engineering rationale (e.g., conservation of mass and energy) to obtain a higher-level understanding of a system. Using a bottom-up approach, the input and output flows can be determined, which describe the overall system. 
The datasets are compared, integrated, and used either to calculate parameters or as input variables in material conversion steps. A conversion step $\mathrm{x}=1,2,3, \ldots, \mathrm{n}$, is described by a set of flows $\mathrm{j}=1,2,3, \ldots, \mathrm{n}$ which can be an input I_( $x, j)$, or output O_( $x, j)$, and calculated using one or more variables and parameters. In addition to standard flow estimates, spatial distributions for the city-region districts $\mathrm{k}=1,2,3, \ldots, \mathrm{n}$ were calculated so as to reflect spatial differences.

The system boundaries and conversion steps are chosen to depict the entire urban water and sanitation system, from raw-water intake to final discharge of untreated and treated wastewater. An overview of the 9 steps and 28 flows quantified as part of the study can be found in Figure 1 below. Since all water and sanitation flows are mapped, a complete description of the flows is obtained.

The nine conversion steps are then translated into a series of 34 material flow equations, which are described in the next sections with parameters listed in Table 1 below, alongside related variables and evaluated parameters. In Section 2.2, the methodology to obtain or calculate variable data and parameters is described for a specific area, including the amount of human urine and faeces generated in the context of developing countries. This framework specifies what data needed to be collected, and this can be repeated for other case studies.



Figure 1. Overview of Water, Sanitation and Hygiene (WASH) flow calculations made in the study using mass-balance principles.

\subsubsection{Centralized Source Water Treatment}

The estimates for raw to potable water were based derived from literature values on raw water treatment capacity, W, and treated water values at the plant sites, so as to derive the source water output value from central treatment plants, Equation (1). The parameter value $\propto$ for source water treatment plant efficiency was estimated to be 0.85 based on the difference between capacity and actual treated output.

$$
\mathrm{O}_{1,1}=\propto \mathrm{W}_{1}
$$

It was also assumed that there are no losses in the conversion from raw water to potable water at a central treatment site, such that raw water input equals potable water output, Equation (2), to estimate water abstraction.

$$
\mathrm{I}_{1,1}=\mathrm{O}_{1,1}
$$




\subsubsection{Potable Water Distribution}

The spatial distribution of central water treated supply was estimated using a three-step procedure. First, the total water lost in the pipe line system was established using Equation (3) for distribution losses and Equation (4) for water intake after distribution.

$$
\begin{aligned}
& \mathrm{O}_{2,1, \mathrm{k}}=\phi_{\mathrm{k}} \beta \mathrm{I}_{2,1, \mathrm{k}} \\
& \mathrm{O}_{2,2}=\mathrm{I}_{2,1}-\beta \mathrm{I}_{2,1}
\end{aligned}
$$

The distribution losses were established based on inputs I, a pipe loss parameter $\beta$ representing leaked water, and the distribution of central output to each area $\phi_{\mathrm{k}}$ with index $\mathrm{k}=1,2, \ldots, \mathrm{n}$. The total aggregated supplied values were allocated to districts based on the calculated spatial distribution parameter $\phi$ for each district $k$, from the distribution of population members in piped areas per district including proportional reduction for the percentage of supply days (see online Supplementary Materials C). It was also assumed that the potable water input into distribution was equivalent to output from the central source water treatment plants, Equation (5).

$$
\mathrm{I}_{2,1}=\mathrm{O}_{1,1}
$$

The value for physical losses from pipeline system leakages was from the literature found to be $27 \%$ of treated water volume [16]. The value relates solely to leakage estimates, as opposed to Non-Revenue Water (NRW) which takes into account all unaccounted for water including non-paid usage.

\subsubsection{Domestic Water Use}

Total water use for domestic purposes was established via bottom-up analysis. The population is divided into socio-economic, $\mathrm{m}=1,2, \ldots, \mathrm{n}$ and age groups $\mathrm{p}=1,2, \ldots, \mathrm{n}$ to differentiate between water user types. The total water use is based on the multiplication of a parameter, $\gamma$, denoting water consumption in liters per capita for a socio-economic group, with the number of people $\mathrm{P}$ in a socio-economic group, resulting in Equation (6). It was further assumed that local losses occurred at a rate of $\delta$ at household sites resulting in Equation (7), converting centrally distributed piped water $\mathrm{I}_{3,1}$ into water losses $\mathrm{O}_{3,1}$. Thereby water available to households (and thereby outputs from households) from centralised water sources become Equation (8), and total available water including local water sourcing is expressed as Equation (9).

$$
\begin{gathered}
\mathrm{I}_{3,1}+\mathrm{I}_{3,2}=\gamma_{\mathrm{m}} \sum_{\mathrm{p}} \mathrm{P}_{\mathrm{m}, \mathrm{p}} \\
\mathrm{O}_{3,1}=\delta \mathrm{I}_{3,1} \\
\mathrm{O}_{3,2}=\mathrm{I}_{3,1}-\mathrm{O}_{3,1} \\
\mathrm{I}_{3,1}+\mathrm{I}_{4,1}=\mathrm{O}_{2,2}
\end{gathered}
$$

To obtain socio-economic groups occupation and employment values were translated into income groupings of low-medium-high income and related to non-drinking water sourcing access per household income category using sequential association, resulting in 30 groups per district, based on the ranking of private pipe access $>$ public tap/stand pipe $>$ protected spring or well or rainfall $>$ tanker/vendor supply $>$ unprotected spring or well or waterbodies in relation to income categories. Subsequently, groups with piped water access were split into rationed and continuous supply using supply rationing proportions to obtain the population $\mathrm{P}_{\mathrm{m}}$ per socio-economic group values for Equation (6). 


\subsubsection{Non-Domestic Water Use}

The total water use for non-domestic purposes was established using Equation (10). The parameter $\varepsilon$ denotes the proportion of central distributed flows $\mathrm{I}_{4,1}$ for non-domestic purposes, which with the addition of locally sourced water $\mathrm{I}_{4,2}$, and output losses $\mathrm{O}_{4,2}$, so as to obtain total non-domestic water use and outputs $\mathrm{O}_{4,1}$. The parameter $\varepsilon$ is differentiated for three sectors of the economy $n=1,2, \ldots, n$ and was based on values of $21 \%, 11 \%$, and $13 \%$ water use share from total GWCL central pipe water supplied by commercial, industrial, and institutional sectors, respectively [16]. Similarly, to domestic water use, a local water loss ratio was assumed using parameter $\zeta$ to obtain water consumed and output from non-domestic users Equation (11). As a result, total non-domestic waste water generation $\mathrm{O}_{4,2}$ can be estimated from water influx $\mathrm{I}_{4,1}$ minus local loss outputs $\mathrm{O}_{4,1}$ resulting in Equation (12).

$$
\begin{gathered}
\mathrm{O}_{4,1}+\mathrm{O}_{4,2}=\varepsilon_{\mathrm{n}} \mathrm{I}_{4,1}+\mathrm{I}_{4,2} \\
\mathrm{O}_{4,1}=\zeta_{\mathrm{n}}\left(\mathrm{I}_{4,1}+\mathrm{I}_{4,2}\right) \\
\mathrm{O}_{4,2}=\mathrm{I}_{4,1}-\mathrm{O}_{4,1}
\end{gathered}
$$

The used water value can be translated to generated wastewater by taking into account on-site losses, such as from evaporation, local leakage, or incorporation into products. Such losses have been estimated to vary between $10 \%$ and $40 \%$ in urban water systems [17]. In the absence of indicative data, a loss value of $10 \%$ was assumed for both the parameter $\delta$ to calculate Equation (7) and parameter $\zeta$ to calculate Equation (11) for domestic and non-domestic losses, respectively.

\subsubsection{Local Water Sourcing}

The values for local water sourcing by decentralised means, such as boreholes, springs, wells and water bodies, were indirectly estimated since technology capacity data is not available. The domestic usage was derived from literature value $D$ for each water source type $O=1,2, \ldots, n$, such that $\mathrm{O}_{5,1}=\mathrm{D}_{\mathrm{o}}$ Equation (13). Company sourcing was determined from the list of licensed users in the water use register of the Water Resources Commission [18]. The number of companies sourcing water locally, $\mathrm{N}_{\mathrm{n}}$, was multiplied by a parameter for the amount sourced $\eta$, resulting in Equation (14). Total local water sourced inputs are equal to both non-domestic and domestic water outputs Equation (15).

$$
\begin{gathered}
\mathrm{O}_{5,1}=\mathrm{D}_{\mathrm{o}} \\
\mathrm{O}_{5,2}=\eta_{\mathrm{n}} \mathrm{N}_{\mathrm{n}} \\
\mathrm{I}_{5,1}=\mathrm{O}_{5,1}+\mathrm{O}_{5,2}
\end{gathered}
$$

\subsubsection{Human Excreta Production}

The amount of urine and faeces generated was based on population members $P_{m, p}$ by age group $\mathrm{p}=1,2, \ldots, \mathrm{n}$ per district $\mathrm{m}=1,2, \ldots, \mathrm{n}$. The values were multiplied by the parameter $\vartheta$ denoting litres of urine excreted per age group resulting in Equation (16), to obtain Urine output $\mathrm{O}_{6,1}$. Similarly for excreta the parameter $\mathrm{k}$ was used denoting faeces excreted per day per age group resulting in Equation (17). It was further assumed that there were no losses between human excreta production and toilet inputs yielding Equations (18) and (19).

$$
\begin{gathered}
\mathrm{O}_{6,1}=\vartheta_{\mathrm{p}} \sum_{\mathrm{m}} \mathrm{P}_{\mathrm{m}, \mathrm{p}} \\
\mathrm{O}_{6,2}=\mathrm{\kappa}_{\mathrm{p}} \sum_{\mathrm{m}} \mathrm{P}_{\mathrm{m}, \mathrm{p}} \\
\mathrm{I}_{8,1}=\mathrm{O}_{6,1}
\end{gathered}
$$




$$
\mathrm{I}_{8,2}=\mathrm{O}_{6,2}
$$

The values used for parameter $\vartheta$ were $1.16 \mathrm{~L}$ and $0.8 \mathrm{~L}$ of urine excreted per day for groups of $15+$ and $0-14$ years, respectively. And for parameter $\mathrm{k}$ values of 0.33 and $0.13 \mathrm{~kg}$ of faeces excreted per day for the 15+ and 0-14 year age groups were used, respectively. The parameter values were derived from a literature review of 15 studies (see online Supplementary Materials A).

\subsubsection{Sewage Discharge at Collection Point}

The calculated wastewater values were translated into discharge into local terrains, open drains, or sewage pipes based on a proportion of wastewater discharged $\lambda$ per discharge route $q=1,2,3$ for generated wastewater. Three discharge routes were assumed $q=1$ for local soils, $q=2$ for open drains, and $q=3$ for sewage pipes, resulting in three equations Equations (20)-(22). Proportions were established from liquid waste disposal census data (see online Supplementary Materials C). The assumptions were made that sewage piped wastewater is routed towards treatment systems, open drain discharge is disposed into waterbodies, and local terrain discharge enters soils.

$$
\begin{aligned}
& \mathrm{O}_{7,1}=\lambda_{\mathrm{q}=1} \mathrm{I}_{7,1} \\
& \mathrm{O}_{7,2}=\lambda_{\mathrm{q}=2} \mathrm{I}_{7,1} \\
& \mathrm{O}_{7,3}=\lambda_{\mathrm{q}=3} \mathrm{I}_{7,1}
\end{aligned}
$$

\subsubsection{Toilet Use}

The discharge of human excreta $\mathrm{I}_{8,3}$ starts with the sum of urine and faeces inputs Equation (23). First, the proportion of inputs to outputs in terms of toilet types $\mu_{\mathrm{r}}$ were established based on $\mathrm{r}=1$ for open defecation, $r=2$ for pan and bucket latrines, $r=3$, for private water closets, $r=4$ for pit latrines and septic tanks, and $r=5$ for public toilets. A combined output route for open defecation and pan and bucket latrines Equation (24), was made, since these are not connected to sewage systems. Also a combined output route was made for private water closets and public toilets Equation (25), as a proportion of these are connected to the centralised sewage system. The third route is for pit latrines, which are emptied by cesspit tanker vehicles.

$$
\begin{gathered}
\mathrm{I}_{8,3}=\mathrm{I}_{8,1}+\mathrm{I}_{8,2} \\
\mathrm{O}_{8,1}=\left(\mu_{1}+\mu_{2}\right) \mathrm{I}_{8,3} \\
\mathrm{O}_{8,4}=\lambda_{\mathrm{r}}\left(\mu_{3}+\mu_{5}\right) \mathrm{I}_{8,3}
\end{gathered}
$$

Leakage losses into the sub-soil were estimated using Equation (26). The equation takes the loss proportion based on a private systems subsoil leakage rate $\xi$, and a public systems leakage rate $v$, and multiplies it with the total excreta discharge $\mathrm{I}_{8,3}$ accounting for the proportion routed to private toilets not connected to central sewage systems $\left(1-\lambda_{r}\right) \mu_{3}$, the proportion of pit latrines $\mu_{4}$, and the proportion of public toilets not connected to sewage systems $\left(1-\lambda_{r}\right) \mu_{5}$, with the parameter $\lambda_{\mathrm{r}}$ denoting the proportion of water closets and public toilets connected to sewage systems. It was assumed that the human excreta that was not leaked was collected by cesspit emptier vehicles for further treatment or disposal Equation (27).

$$
\begin{gathered}
\mathrm{O}_{8,2}=\left(\xi\left(\left(1-\lambda_{\mathrm{r}}\right) \mu_{3}+\mu_{4}\right)+v\left(1-\lambda_{\mathrm{r}}\right) \mu_{5}\right) \mathrm{I}_{8,3} \\
\mathrm{O}_{8,3}=\left((1-\xi)\left(\left(1-\lambda_{\mathrm{r}}\right) \mu_{3}+\mu_{4}\right)+(1-v)\left(1-\lambda_{\mathrm{r}}\right) \mu_{5}\right) \mathrm{I}_{8,3}
\end{gathered}
$$

The equations takes into account that in case of pit latrine or septic tanks systems discharge, it was taken into account that a large liquid share will drain into the sub-surface due to bottom latrine 
porosity and septic drain field discharge. The sub-soil drainage rate was assumed different for public and private toilet systems because public systems have better structures which are more efficiently enclosed and emptied within weeks to months, whilst private systems typically have more porous structures and are emptied once every five to ten years. Values were established at $87 \%$ leakage for sub-soil leakage from private systems $\xi$, and $50 \%$ for leakage from public systems $v$, based on literature values [19-25].

\subsubsection{Sewage Treatment}

The proportion of sewage treated in centralized treatment plants was established in two ways. First, the proportion of wastewater treated in sewage plants, and proportion of human excreta treated in sewage plants was established, from the three input routes cesspit emptier collection Equation (28), centralised piped intake of human excreta Equation (29), and for centralized piped intake of wastewater Equation (30).

$$
\begin{aligned}
& \mathrm{I}_{9,3}=\mathrm{O}_{8,3} \\
& \mathrm{I}_{9,2}=\mathrm{O}_{8,4} \\
& \mathrm{I}_{9,1}=\mathrm{O}_{7,3}
\end{aligned}
$$

Thereby taking into account the proportion $\varrho$ of wastewater which is centrally treated, and $\sigma$, the proportion of human excreta that is centrally treated, this results in the amount of centrally treated Sewage Equation (31). The residual sewage is not treated and disposed of at cesspit emptier truck dump sites, or by direct discharge into the sea or other water bodies, as represented by Equation (32). These values should match up with the top-down calculation of sewage treated in centralised waste water treatment plants, based on operational sewage treatment capacity $S_{S}$, and the sewage treatment plant efficiency $v_{s}$, for each technology $s=1,2, \ldots, n$. Thereby the treatment output should equate to Equation (33). Finally, the sum of treated and untreated discharged outputs should be equivalent to inputs from the three input routes cesspit emptiers, centralised piped human excreta intake, and centralised piped wastewater intake Equation (34).

$$
\begin{gathered}
\mathrm{O}_{9,1}=\sigma\left(\mathrm{I}_{9,1}+\mathrm{I}_{9,3}\right)+\varrho \mathrm{I}_{9,2} \\
\mathrm{O}_{9,2}=(1-\sigma)\left(\mathrm{I}_{9,1}+\mathrm{I}_{9,3}\right)+(1-\varrho) \mathrm{I}_{9,2} \\
\mathrm{O}_{9,1}=v_{\mathrm{s}} \mathrm{S}_{\mathrm{s}}\left(\sigma\left(\mathrm{I}_{9,1}+\mathrm{I}_{9,3}\right)+\varrho \mathrm{I}_{9,2}\right) \\
\mathrm{O}_{9,1}+\mathrm{O}_{9,2}=\mathrm{I}_{9,1}+\mathrm{I}_{9,2}+\mathrm{I}_{9,3}
\end{gathered}
$$

The treatment capacity of sewage plants per technology was evaluated by creating an inventory of treatment plants, starting with a survey carried out in 2011-2012 on the operational status of all sewage treatment plants (STPs) in GAMA [26], which for this paper was reviewed and updated with newer studies and local news report updates as referenced in the results. 
Table 1. Overview of variables and parameters established in the study.

\begin{tabular}{|c|c|c|c|c|c|c|c|}
\hline \multicolumn{2}{|c|}{ Conversion Description } & \multirow{3}{*}{$\begin{array}{c}\text { Equation No. } \\
(1) \\
(2)\end{array}$} & \multirow{3}{*}{$\begin{array}{c}\text { Variables Description } \\
\begin{array}{c}\mathrm{W}_{\mathrm{l}} \text {, raw water treatment capacity by } \\
\text { technology }\end{array}\end{array}$} & \multirow{3}{*}{$\begin{array}{c}\text { Parameters Description } \\
\alpha, \text { source water treatment plant efficiency }\end{array}$} & \multirow{3}{*}{$\begin{array}{c}\text { Parameters Established } \\
\propto \alpha=0.85\end{array}$} & \multirow{3}{*}{$\begin{array}{c}\text { Uncertainty } \\
\begin{array}{c}\text { Low-typical for maintained } \\
\text { plants }\end{array}\end{array}$} & \multirow{3}{*}{$\begin{array}{l}\text { See Section } \\
(2.1 .1,2.2 .2)\end{array}$} \\
\hline 1 & Source water & & & & & & \\
\hline 1 & treatment & & & & & & \\
\hline \multirow{3}{*}{2} & \multirow{3}{*}{$\begin{array}{l}\text { Potable water } \\
\text { distribution }\end{array}$} & (3) & & \multirow{3}{*}{$\begin{array}{c}\beta, \text { pipe loss parameter } \\
\phi, \text { spatial distribution parameter with } \\
\text { proportion of supply per area } \mathrm{k}\end{array}$} & $\beta=0.27$ & $\begin{array}{l}\text { High-no measured information, } \\
\text { inferred value }\end{array}$ & $(2.1 .2,2.2 .3)$ \\
\hline & & $(4)$ & & & $\phi=0$ to 0.66 & Low—measured values for & (Supplementary \\
\hline & & (5) & & & & proportion delivery to areas & Material C) \\
\hline \multirow{4}{*}{3} & \multirow{4}{*}{$\begin{array}{l}\text { Domestic water } \\
\text { use }\end{array}$} & (6) & \multirow{4}{*}{$\begin{array}{l}\text { P, population members per } \\
\text { socio-economic } \mathrm{m} \text { and age group } \mathrm{p}\end{array}$} & \multirow{2}{*}{$\begin{array}{l}\gamma, \text { water consumption in litres per capita } \\
\text { by socio-economic group m }\end{array}$} & \multirow{2}{*}{$\gamma=32$ to 138} & \multirow{2}{*}{$\begin{array}{c}\text { Medium-estimates from } \\
\text { triangulation of GAMA case } \\
\text { studies }\end{array}$} & \multirow{2}{*}{$(2.1 .3,2.2 .4)$} \\
\hline & & (7) & & & & & \\
\hline & & $(8)$ & & $\delta$, local water losses at household site & $\delta=0.10$ & Medium—-single & $(2.1 .3,2.2 .4)$ \\
\hline & & (9) & & & $0-0.10$ & estimates-inferred value & $(2.1 .3,2.2 .4)$ \\
\hline \multirow{3}{*}{4} & \multirow{3}{*}{$\begin{array}{l}\text { Non-domestic } \\
\text { water use }\end{array}$} & $(10)$ & & \multirow{2}{*}{$\begin{array}{l}\varepsilon, \text { proportion of distributed water used } \\
\text { by non-domestic users by sector } n\end{array}$} & \multirow{2}{*}{$\begin{aligned} \varepsilon= & 0.27,0.11, \\
& 0.13\end{aligned}$} & \multirow{2}{*}{$\begin{array}{l}\text { Medium-estimates from Ghana } \\
\text { Water Company Limited }\end{array}$} & \multirow{2}{*}{$(2.1 .4,2.2 .4)$} \\
\hline & & (11) & & & & & \\
\hline & & (12) & & $\begin{array}{l}\zeta, \text { local water losses at non-domestic sites } \\
\text { by sector } n\end{array}$ & $\zeta=0.10$ & $\begin{array}{c}\text { Medium-single } \\
\text { estimates-inferred values }\end{array}$ & $(2.1 .4,2.2 .4)$ \\
\hline \multirow{3}{*}{5} & \multirow{3}{*}{$\begin{array}{l}\text { Local water } \\
\text { sourcing }\end{array}$} & (13) & $\begin{array}{l}\mathrm{D}_{\mathrm{o}} \text {, local domestic water sourcing } \\
\text { capacity by source type o }\end{array}$ & & & & (2.1.5) \\
\hline & & (14) & \multirow{2}{*}{$\begin{array}{c}N_{n}, \text { number of companies sourcing } \\
\text { water locally per sector } n\end{array}$} & \multirow{2}{*}{$\begin{array}{c}\eta \text {, amount of water sourced per company } \\
\text { in sector } n\end{array}$} & \multirow{2}{*}{$\eta=1000$} & \multirow{2}{*}{$\begin{array}{l}\text { High-Top-down approximate } \\
\text { estimate }\end{array}$} & \multirow{2}{*}{$(2.1 .5,2.2 .4)$} \\
\hline & & (15) & & & & & \\
\hline \multirow{4}{*}{6} & & (16) & & $\vartheta$, amount of urine excreted per unit time & $\vartheta=1.16,0.8$ & Low_-based on $15+$ studies & $(2.1 .6,2.2 .5)$ \\
\hline & Human excreta & $(18)$ & $\mathrm{P}$, population members per & $\begin{array}{c}\text { i.e., litres per day per person for } 15+\text { and } \\
0-14 \text { vear age groups } p\end{array}$ & & literature survey & $\begin{array}{l}\text { (Supplementary } \\
\text { Material A) }\end{array}$ \\
\hline & production & (17) & socio-economic $m$ and age group $p$ & K, amount of faeces excreted per unit & $\kappa=0.33,0.13$ & Low_based on $15+$ studies & $(2.1 .6,2.2 .5)$ \\
\hline & & (19) & & $\begin{array}{l}\text { tıme 1.e., k1lograms per day per person } \\
\text { for } 15+\text { and } 0-14 \text { year age groups } p\end{array}$ & & literature survey & $\begin{array}{l}\text { (Suppiementary } \\
\text { Material A) }\end{array}$ \\
\hline & & $(20)$ & & $\lambda_{\mathrm{q}}$, proportion of wastewater discharged & $\lambda_{\mathrm{q}=1}=0.43$ to 0.93 & & $(2.1 .7,2.2 .6)$ \\
\hline 7 & at collection point & (21) & & onto local soils $\mathrm{q}=1$, into open drains & $\lambda_{\mathrm{q}=2}=0.02$ to 0.30 & $\begin{array}{l}\text { calculation value } \\
\text { cold }\end{array}$ & (Supplementary \\
\hline & & (22) & & $\mathrm{q}=2$, and into sewage pipes $\mathrm{q}=3$ & $\lambda_{\mathrm{q}=3}=0.01$ & & Material C) \\
\hline & & (23) & & population nronortion practicing & $\mu_{\mathrm{r}=1}=0.04$ to 0.25 & & \\
\hline & & $(24)$ & & $\begin{array}{l}\mu_{\mathrm{r}}, \text { populatation proportion practicing } \\
\text { open defaecation } \mathrm{r}=1 \text {, using pan and }\end{array}$ & $\begin{array}{l}\mu_{\mathrm{r}=2}=0.00 \text { to } 0.04 \\
\mu_{\mathrm{r}=3}=0.09 \text { to } 0.53\end{array}$ & Low-census data + inferred & $\begin{array}{c}(2.1 .8,2.2 .6) \\
\text { Supplementary }\end{array}$ \\
\hline & & (25) & & $\begin{array}{l}\text { bucket latrines } r=2 \text {, private w.c. } r=3 \text {, } \\
\text { pit latrines } r=4 \text {, and public toilets } r=5\end{array}$ & $\begin{array}{l}\mu_{\mathrm{r}=3}=0.02 \text { to } 0.40 \\
\mu_{\mathrm{r}=4}=0.06 \text { to } 0.64\end{array}$ & calculation value & $\begin{array}{l}\text { (Supplementary } \\
\text { Material C) }\end{array}$ \\
\hline 8 & Toilet use & (26) & & $\begin{array}{l}\lambda_{\mathrm{r}=1} \text {, proportion of w.c. and public } \\
\text { toilets connected to sewage system }\end{array}$ & & & $(2.1 .8)$ \\
\hline & & (27) & & $\begin{array}{l}\xi \text {, sub-soil leakage from privately used } \\
\text { septic tanks and pit latrines }\end{array}$ & $\xi=0.87$ & $\begin{array}{l}\text { Low—multi-site studies with } \\
\text { leakage measurements }\end{array}$ & $(2.1 .8,2.2 .6)$ \\
\hline & & & & $\begin{array}{l}v \text {, sub-soil leakage from publicly used } \\
\text { septic tanks and pit latrines }\end{array}$ & $v=0.50$ & $\begin{array}{l}\text { Low-multi-site studies with } \\
\text { leakage measurements }\end{array}$ & $(2.1 .8,2.2 .6)$ \\
\hline
\end{tabular}


Table 1. Cont.

\begin{tabular}{|c|c|c|c|c|c|c|}
\hline Conversion Description & Equation No. & Variables Description & Parameters Description & Parameters Established & Uncertainty & See Section \\
\hline \multirow{5}{*}{$\begin{array}{l}\text { Sewage treatment } \\
\text { systems }\end{array}$} & (28), (29), (30) & \multirow{5}{*}{$\begin{array}{l}\mathrm{S}_{\mathrm{S}} \text {, operational sewage treatment } \\
\text { capacity by technology } \mathrm{s}\end{array}$} & $\begin{array}{l}\rho, \text { proportion of wastewater treated in } \\
\text { sewage plants }\end{array}$ & $\rho=<0.01$ & \multirow{2}{*}{$\begin{array}{l}\text { Low-triangulated study } \\
\text { estimates \& inferred values }\end{array}$} & $(2.1 .9,2.2 .7)(3.6)$ \\
\hline & (31) & & $\begin{array}{c}\sigma, \text { proportion of human excreta treated in } \\
\text { sewage plants }\end{array}$ & $\sigma=0.0$ & & $(2.1 .9,2.2 .7)(3.6)$ \\
\hline & (32) & & \multirow{3}{*}{$\begin{array}{l}v \text {, sewage treatment plant efficiency by } \\
\text { technology s }\end{array}$} & \multirow{3}{*}{$\begin{array}{c}v=0.12 \\
\text { to } 0.85\end{array}$} & \multirow{3}{*}{$\begin{array}{l}\text { Low-typical for maintained } \\
\text { plants }\end{array}$} & \multirow{3}{*}{$(2.1 .9,2.2 .7)(3.6)$} \\
\hline & (33) & & & & & \\
\hline & (34) & & & & & \\
\hline
\end{tabular}




\subsection{Application to the Greater Accra Metropolitan Area}

The study subject GAMA was defined on the basis of the administrative districts governed by assemblies with decentralized power by the Government of Ghana since 1993 [27]. The geographic boundary definition of GAMA as a city region used in this paper was defined by local stakeholders using the Metropolitan and Municipal District Assembly (MMDA) structures in the country [10]; for details, see Table S1 in Supplementary Material C. The definition includes 15 districts, with the Accra and Tema Metropolitan Districts as the most populous and home to the majority of economic activity. The used spatial outline of MMDAs in GAMA is shown in Figure 2, and the historic boundary development of the MMDAs since 1988 can be found in the online Supplementary Material A. The year 2010 was selected as the year of analysis as this is the last year with baseline data from the Ghanaian Census; nevertheless, more recent figures were included when available.

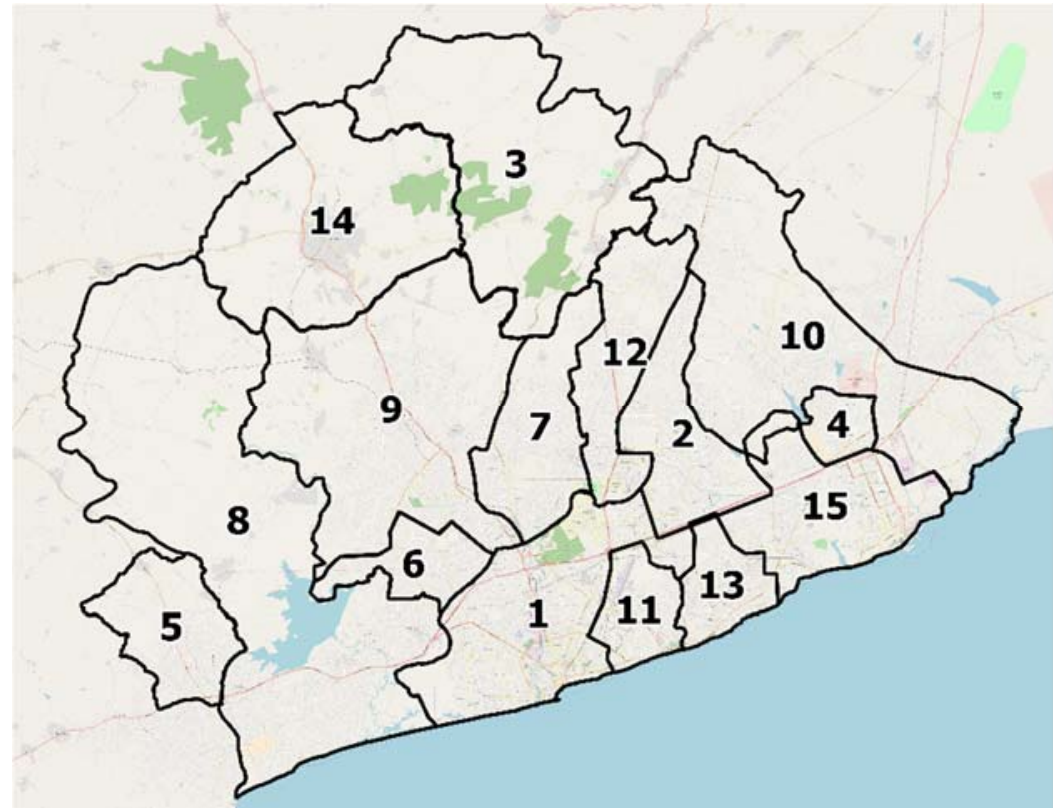

1. Accra Metropolitan

2. Adentan

3. Akwapim South

4. Ashaiman

5. Awutu Senya East

6. Ga Central

7. Ga East

8. Ga South

9. Ga West

10. Kpone Katamanso

11. La Dade Kotopon

12. La Nkwantanang Madina

13. Ledzokuku Krowor

14. Nsawam Adoagyiri

15. Tema Metropolitan

Figure 2. Boundaries of Greater Accra Metropolitan Area (GAMA) administrative regions from 2012 onwards.

\subsubsection{Data Collection and Integration}

The data required for WASH descriptive modelling as specified by the framework was sourced from documentation and from local authorities and water company officers. For data collection from documentation, several hundred literature studies, reports, news articles, and media reports were screened, out of which key datasets were incorporated into the study, in order to provide the most comprehensive quantification feasible within the limited data availability. The data screening criteria included: (1) time—-data post 2008 was considered, (2) location—data relevant to GAMA was taken into account; (3) system boundaries-data with clearly defined system boundaries and units was preferred. The flow assessment was limited to the year 2010, primarily due to availability of household infrastructure use data from the Ghana Statistical Service [28-42]. If data from recent years were available, these were incorporated into the study. Moreover, as part of the study, contact was sought with local officers in GAMA at the Ghana Water Company Limited (GWCL) to update water treatment, pipeline system, and rationing data (GWCL, Managing Director Frederick Christian Lokko, personal communication, 19 November 2015). In addition to WASH flow data, surface water quality measurements were collected and integrated from the literature to provide for a summary of known datasets in this domain. The data were collected and integrated in MS Excel spreadsheets and in 
QGIS [43] for spatial mapping purposes. The calculations were carried out in MS Excel for each of the 15 MMDAs, and subsequently aggregated to provide for the total GAMA estimates.

\subsubsection{Raw Water to Source Water}

The estimates for raw to potable water were derived from literature values on raw water treatment capacity and treated water values at the plant sites. The three central water treatment sites, (see Table 2), operating in GAMA informed the treatment capacity value $\mathrm{W}$ in Equation (1).

Historic figures for treated potable water supplied into the centralised distribution network were taken from $[15,44,45]$ and complemented with 2014 plus 2015 values provided by GWCL. The parameter value $\propto$ for source water treatment plant efficiency was estimated to be 0.85 based on the difference between capacity and actual treated output.

The values for local water sourcing by decentralised means, such as boreholes, springs, wells and water bodies, were indirectly estimated since technology capacity could not be located. The domestic usage was derived from total bottom-up use estimates (see Supplementary Material C), and company sourcing was determined from the list of licensed users in the water use register of the Water Resources Commission [18]. The number of companies sourcing water locally, $\mathrm{N}_{\mathrm{n}}$, as per Equation (14), was thereby estimated to be 7 within the GAMA region. The parameter for the amount-sourced $\eta$ was conservatively estimated at $1000 \mathrm{~m}^{3}$ per day for each company.

Table 2. Overview of potable water treatment plants in GAMA.

\begin{tabular}{|c|c|c|c|c|c|c|c|}
\hline $\begin{array}{l}\text { Treatment } \\
\text { Plant Sites }\end{array}$ & $\begin{array}{l}\text { Water } \\
\text { Source }\end{array}$ & Technology * & $\begin{array}{c}\text { Year of } \\
\text { Opening }\end{array}$ & $\begin{array}{l}\text { Year of } \\
\text { Expansion }\end{array}$ & $\begin{array}{c}\text { Capacity in } 2010 \\
\left(\mathrm{~m}^{3} \text { per day }\right)\end{array}$ & $\begin{array}{l}\text { Capacity in } 2015 \\
\left(\mathrm{~m}^{3} \text { per day }\right)\end{array}$ & $\begin{array}{c}\text { Source of } \\
\text { Data }\end{array}$ \\
\hline Weija & Weija lake & $\begin{array}{l}\text { Conventional } \\
\text { chemical water } \\
\text { treatment }\end{array}$ & 1951 & $\begin{array}{l}1978,1984 \\
2002,2009\end{array}$ & 245,484 & 245,484 & [44-49] \\
\hline Kpong & Volta river & $\begin{array}{l}\text { Conventional } \\
\text { chemical water } \\
\text { treatment }\end{array}$ & 1963 & $\begin{array}{l}1965,1995 \\
2015\end{array}$ & 220,454 & 434,454 & {$[44,45,50-53]$} \\
\hline Teshie & Sea & Desalination & 2015 & - & - & 60,000 & [54] \\
\hline
\end{tabular}

\subsubsection{Source Water Distribution}

The spatial distribution of central water treated supplies was estimated using a three-step procedure. First, the total water lost in the pipeline system was established using the pipe loss parameter $\beta$ and Equations (3) and (4). The value for physical losses from the pipeline system leakages was from the literature and found to be $27 \%$ of treated water volume [16]. The value relates solely to leakage estimates, as opposed to Non-Revenue Water (NRW), which takes into account all unaccounted-for water including non-paid usage. Second, the spatial areas and population therein with continuous piped supply and 2+ days of rationed supply per week were calculated including the percentage of days with no supply. The spatial maps and allocation (see Figure 3) were created on the basis of a piped area and a rationing scheme map obtained from GWCL, and census population data [28-42]. The rationing scheme in place is imposed on approximately $63 \%$ of the area with central pipe supply. Finally, the total aggregated supplied values were allocated to districts based on the calculated spatial distribution parameter $\phi$ for each district $k$, from the distribution of population members in piped areas per district including proportional reduction for the percentage of supply days (see online Supplementary Material C). 


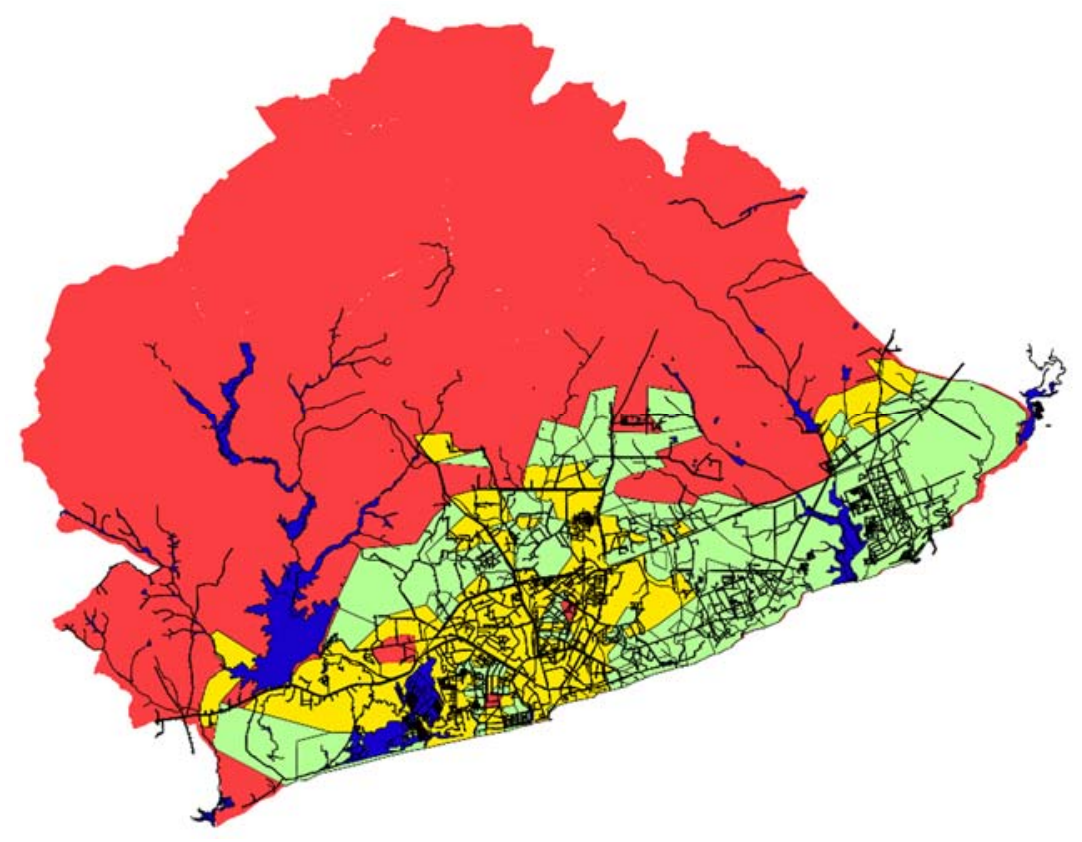

Figure 3. Zones in GAMA supplied by the pipe and rationing scheme as of August 2015 (areas with no access to pipe supply (red), areas with continuous pipe supply (blue), areas with rationed supply (yellow), water bodies (turquoise), and the pipe network (dark lines)). Source of data: Ghana Water Company Limited (GWCL), Accra, Ghana, map data (C) OpenStreetMap contributors.

\subsubsection{Potable Water Use and Local Sourcing}

The total water use for non-domestic purposes was established via the parameter $\varepsilon$ for proportion of central distributed flows used for non-domestic purposes. The parameter was based on values of $21 \%, 11 \%$, and $13 \%$ water use share from total GWCL central pipe water supplied by commercial, industrial, and institutional sectors, respectively [16]. Total water use for domestic purposes was established via bottom-up analysis.

Firstly, socio-economic groups were established per district using population numbers for employment status, occupation, and non-drinking water sourcing [28-42]. The occupation and employment values were translated into income groupings of low-medium-high income and related to non-drinking water sourcing access per household income category. The method was sequential association, resulting in 30 groups per district, based on the ranking of private pipe access $>$ public tap/stand pipe $>$ protected spring or well or rainfall $>$ tanker/vendor supply $>$ unprotected spring or well or waterbodies in relation to income categories. Subsequently, groups with piped water access were split into rationed and continuous supply using supply rationing proportions (Supplementary Material C) to obtain the population $P_{\mathrm{m}}$ per socio-economic group values for Equation (6).

Secondly, to achieve the demand data, the number of people in each group was multiplied by a water consumption per capita value, taking into account the income status and supply type. The values used for the parameter $\gamma$, water consumption per capita by socio-economic group, are summarised in Table 3 as obtained from four literature studies [55,56].

Thirdly, per capita use values per socio-economic group were multiplied by population numbers and aggregated to the district level to obtain total water use and sourcing categories including decentralised, improved protected, unimproved decentralised, and tanker/vendor-based pipe supply. Decentralised pipe-based supply was calculated by subtracting central pipe supply delivered (Section 2.2.3) from total domestic pipe supply as calculated, including correction for supply to non-domestic customers. 
Table 3. Water consumption in litres per capita per day by income, sourcing condition and source type. Source of data: [55-58].

\begin{tabular}{ccccc}
\hline Sourcing Condition & Source Type & Low Income & Medium Income & High Income \\
\hline Continuous piped water access & Piped water source & 66 & 90 & 138 \\
\hline Good intermittent piped water & Piped water source & 56 & 83 & 110 \\
access $(80 \%+$ time available) & Secondary source & 0 & 0 & 28 \\
\hline $\begin{array}{c}\text { Poor intermittent piped water } \\
\text { access }(<50 \% \text { time available) }\end{array}$ & $\begin{array}{c}\text { Piped water source } \\
\text { Secondary source }\end{array}$ & 43 & 54 & 75 \\
\hline $\begin{array}{c}\text { No piped water } \\
\text { access } / \text { decentralised source }\end{array}$ & Secondary decentralised & \multirow{2}{*}{32} & 53 & 53 \\
\hline
\end{tabular}

\subsubsection{Wastewater and Human Excreta Generation}

The used water value can be translated into generated wastewater by taking into account on-site losses, such as from evaporation, local leakage, or incorporation into products. Such losses have been estimated to vary between $10 \%$ and $40 \%$ in urban water systems [17]. In the absence of indicative data, a loss value of $10 \%$ was assumed for both the parameter $\delta$ in Equation (7) and parameter $\zeta$ in Equation (11) for domestic and non-domestic losses, respectively.

The amount of urine and faeces generated was based on population members by age group $\mathrm{P}_{\mathrm{m}, \mathrm{p}}$ per district. The values were multiplied by the parameter $\vartheta$ values of $1.16 \mathrm{~L}$ and $0.8 \mathrm{~L}$ of urine excreted per day for groups of 15+ and 0-14 years, respectively, and by the parameter $k$ values of 0.33 and $0.13 \mathrm{~kg}$ of faeces excreted per day for the 15+ and 0-14 year age groups, respectively. The parameter values were derived from a literature review of 15 studies (see online Supplementary Material A).

\subsubsection{Sanitation and Sewage Collection}

The calculated wastewater values were translated into discharge into local terrains, open drains, or sewage pipes. The proportions per discharge route $\lambda_{\mathrm{q}}$ for generated wastewater for Equations (21)-(23) were established from liquid waste disposal census data [28-42] (see online Supplementary Material C). The assumptions were made that sewage piped wastewater is routed towards treatment systems, open drain discharge is disposed into waterbodies, and local terrain discharge enters soils.

The discharge of human excreta was informed by the parameter $\mu_{\mathrm{r}}$ describing the proportion of toilet types used by the population with data from [28-42] (see online Supplementary Material C). The excreta routed into water closet (W.C.) was split into two groups: W.C. connected to sewage systems, and W.C. connected to septic tanks, expressed via proportions using the parameter $\lambda_{\mathrm{q}}$ based on liquid waste disposal data [28-42]. In the case of pit latrine or septic tanks systems discharge, it was taken into account that a large liquid share will drain into the sub-surface due to bottom latrine porosity and septic drain field discharge. The sub-soil drainage rate was assumed different for public and private toilet systems, because public systems have better structures which are more efficiently enclosed and contained, and emptied within weeks to months, whilst private systems typically have more porous leak-prone structures and are emptied once every five to ten years. Values were established at $87 \%$ leakage for sub-soil leakage from private systems $\xi$, and $50 \%$ for leakage from public systems $v$, based on literature values $[19,21,23]$.

\subsubsection{Sewage Treatment}

The treatment of sewage was calculated by creating an inventory of treatment plants, their technology and capacity. The main dataset was taken from a survey carried out in 2011-2012 on the operational status of all sewage treatment plants (STPs) in GAMA [26], which, for this publication, was reviewed and updated with newer studies and local news report updates as referenced in the results.

\section{Results: Water, Sanitation and Hygiene Data for the Greater Accra Metropolitan Area in Ghana}

The complete year 2010 analysis results for the GAMA are presented in Figures 4 and 5 as Sankey diagrams below, from raw water to wastewater discharge, and from human excreta generation to 
discharge, respectively. The results for individual components and districts are presented in detail in Sections 3.1-3.6 below. An overview of parameters established to carry out the material flow analysis is provided in Table 1, as described in Section 2.1. The areas in GAMA supplied by the pipe and rationing scheme as of August 2015 are shown in Figure 3. The evolution of total central water treatment capacity in GAMA from 1980 to 2015 is displayed in Figure S1 in Supplementary Material B. The domestic water use in the districts of GAMA in 2010 is shown in Figure S2 in Supplementary Material B. The wastewater and human excreta generation estimates in GAMA per district for 2010 by sink are provided in Figure S3 in Supplementary Material B. The proportions of wastewater and human excreta ending up in the environment and collected via sewage pipes and cesspit-tankers are illustrated in Figure S4 in Supplementary Material B. Figures S1-S4 are available in Supplementary Material B.

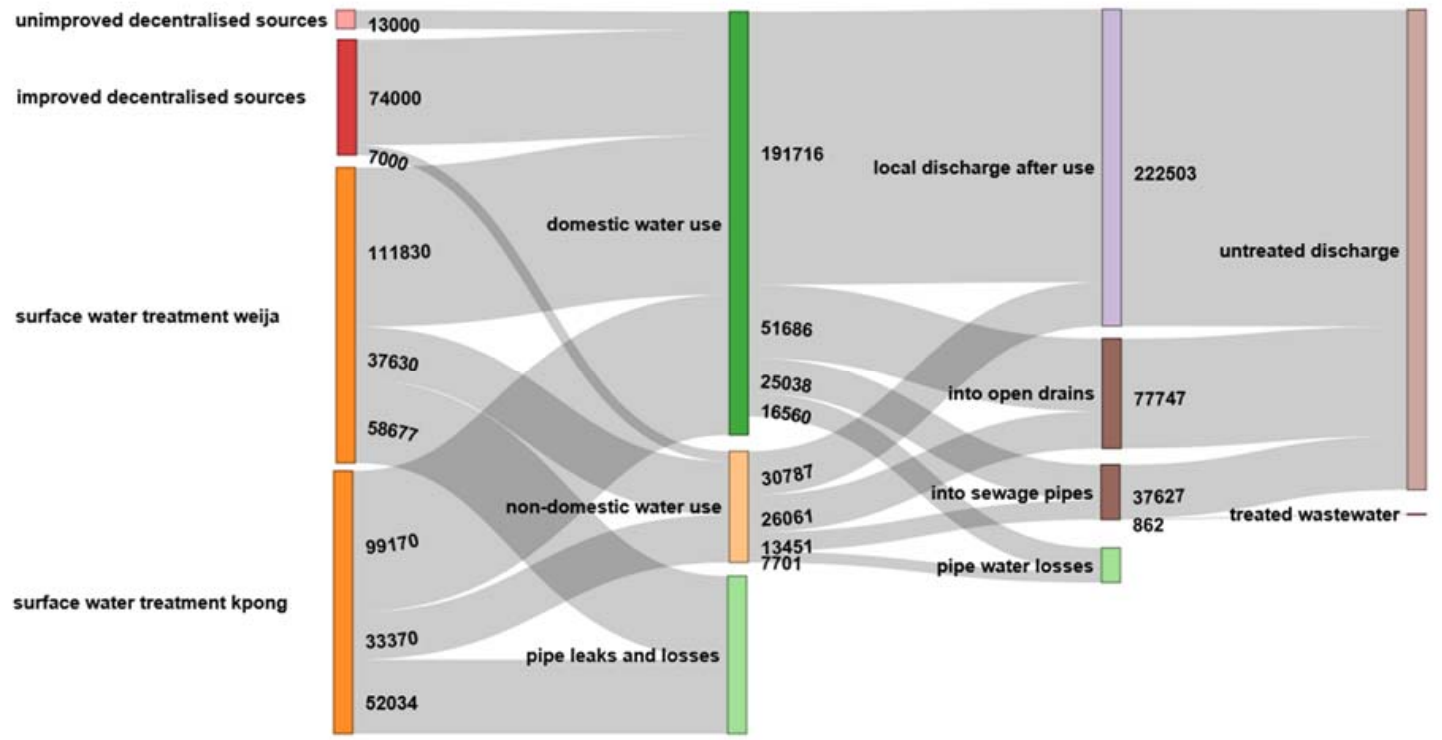

Figure 4. Sankey diagram from 2010 GAMA raw water treatment to final wastewater discharge flows in $\mathrm{m}^{3}$ per day.

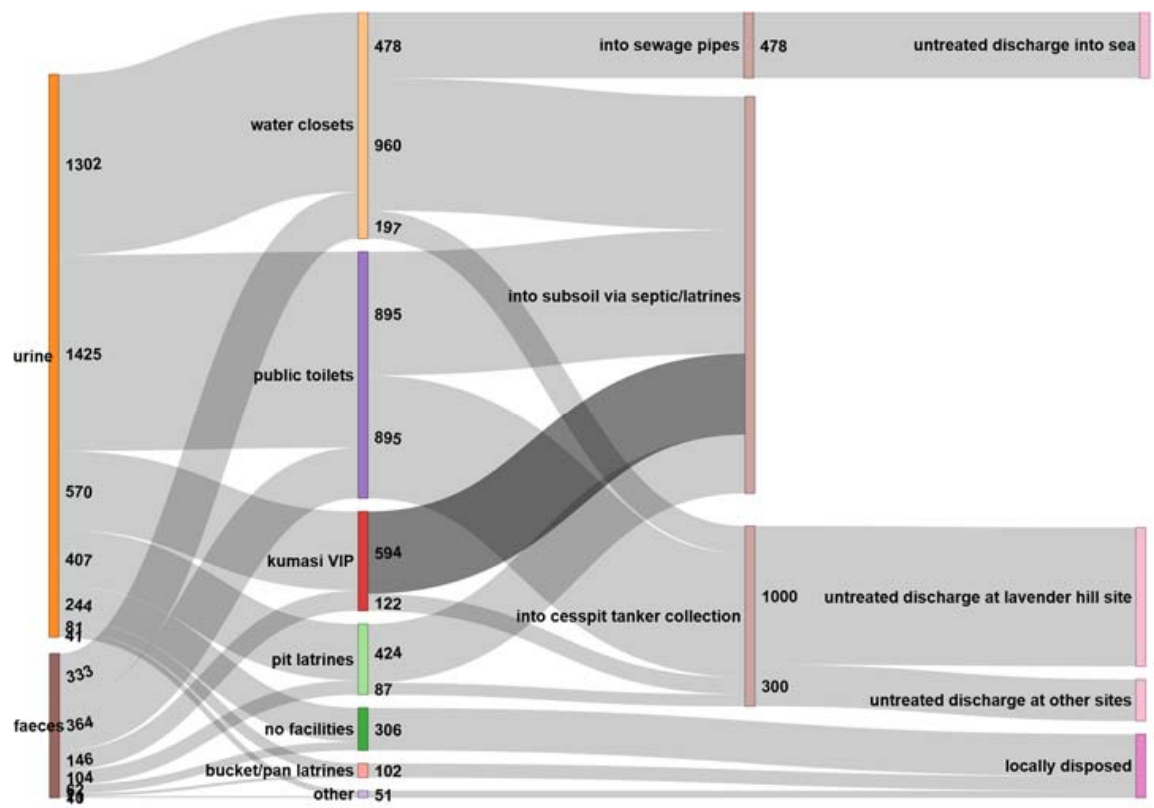

Figure 5. Sankey diagram from 2010 GAMA human excreta generation to final discharge flows in $\mathrm{m}^{3}$ per day. A Kumasi Ventilated Improved Pit (VIP) is designed with two pits versus a single-pit VIP. 


\subsection{Central Source Water Treatment and Distribution}

The calculated 1980-2015 GAMA central water treatment capacity is shown below in Figure 6A, as well as total estimated water supply to GAMA residents from 1980 to 2015 (Figure 6B), and the 2010 distribution per district (Figure 6A). The results showed that total water supplied increased by $40 \%$ from 2010 to 2015 , or from 285 to $374 \mathrm{~m}^{3}$ per day, due to expansions at Kpong treatment and the Teshie desalination plant opening. In total, the central pipe network supplied $\sim 66 \%$ of the population with potable water in 2010, and approximately 50\% utilised it as their main drinking water source. The $\sim 16 \%$ difference is plausibly explained by diminished water quality due to ageing metal pipes introducing rust, occasional soil plus faecal contamination from burst pipes, and general distrust of pipe-supplied water from previous contamination incidents [59-61]. The outcome of the 2014/2015 supply expansion on water access is not clear, beyond that it appears to have significantly improved the water rationing situation that was imposed by GWCL [53].
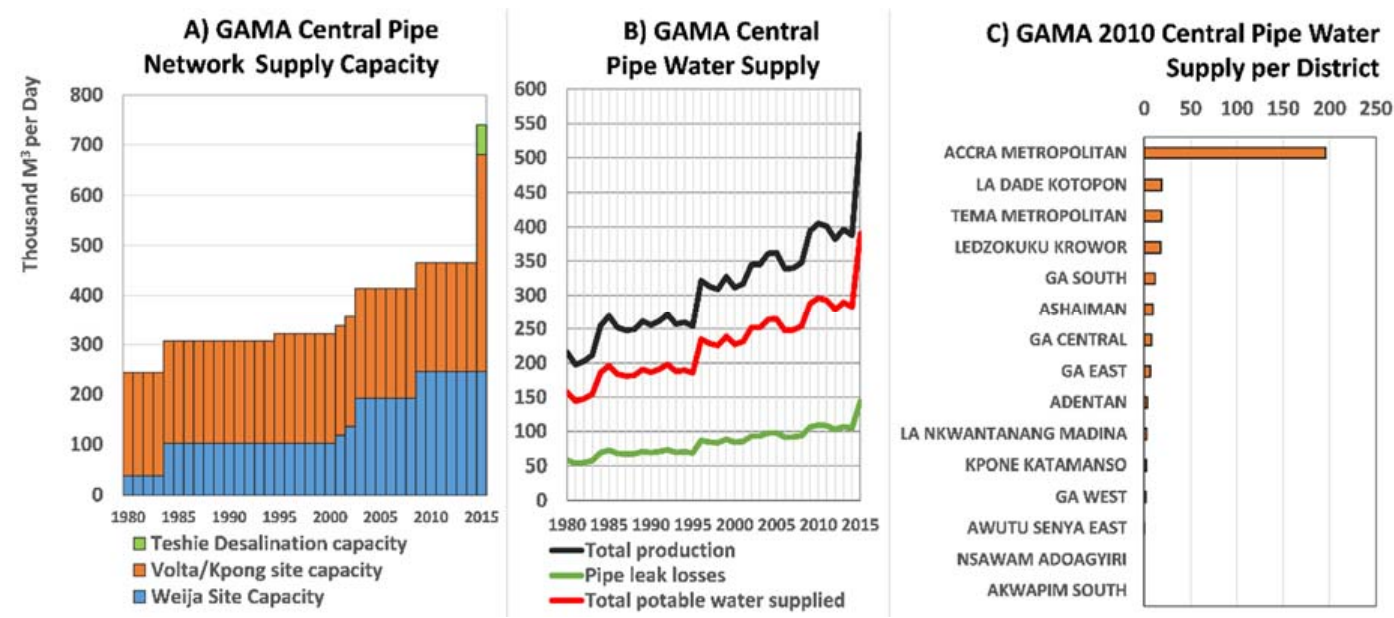

Figure 6. Centrally supplied water in GAMA. (A) Total central water treatment capacity in GAMA in $\mathrm{m}^{3}$ from 1980 to 2015. (B) Total water produced, lost from leaks, and supplied to customers.

(C) Estimated distribution of water supplied per district for 2010.

\subsection{Decentralised Water Sourcing}

To augment central piped supplies, several thousand improved decentralised sources of water have been developed including boreholes, pump and tube-wells, improved wells and improved springs. Often, boreholes are connected to local small town pipe supply systems supplying several hundred to thousands of people. Altogether, these sources were estimated to supply $24 \%$ of households in GAMA with non-drinking water in 2010, and 16\% utilised such sources for drinking water [28-42]. The large majority of decentralised supplies are established in the districts: Ga West, Ga East, Ga South, Nsawam Adoagyiri, Akwapim South, Kpone Katamanso and La-Nkwantanang-Madina. In addition, unprotected local decentralised sources are used including springs, wells, rivers, ponds, and canals, from which $4 \%$ and $1 \%$ of the population obtained their 2010 non-drinking and drinking water supply, respectively [28-42]. Finally, tanker/vendor suppliers of potable water operate in the city-region. The tankers/vendors typically obtain water from GWCL's pipe system and transport it to non-access or rationed areas. They provide non-drinking and drinking water to $6 \%$ and 3\% of the GAMA population, respectively [28-42].

Since the late 1990s, the use of sachet water has grown considerably, as the small $250-500 \mathrm{~mL}$ plastic bags are a conveniently available source of drinking water [14]. Several hundred small to large filling companies of sachet waters have sprung into existence, which supplied sachets to a total of $29 \%$ of households in 2010 as a main drinking water source [28-42]. Bottled water only served 1\% of the population for their drinking water. If sachets and bottled water would be of consistently supplied at high water quality and counted as improved water sources, a total of $96 \%$ of the population had access to improved safe water in 2010, otherwise only 67\% had improved safe water access in 2010. 


\subsection{Domestic and Non-Domestic Water Consumption}

Total domestic water use from all sources was calculated at 298 thousand $\mathrm{m}^{3}$ per day, of which 211 thousand $\mathrm{m}^{3}$ was from the central GWCL pipe system, 74 thousand $\mathrm{m}^{3}$ from improved decentralised sources, and 13 thousand $\mathrm{m}^{3}$ from unimproved decentralised sources. An overview per district is shown in Figure 7 including central pipe, improved decentralised, and unprotected decentralised sources. Total non-domestic supplies were estimated at 77 thousand $\mathrm{m}^{3}$ per day in 2010 .
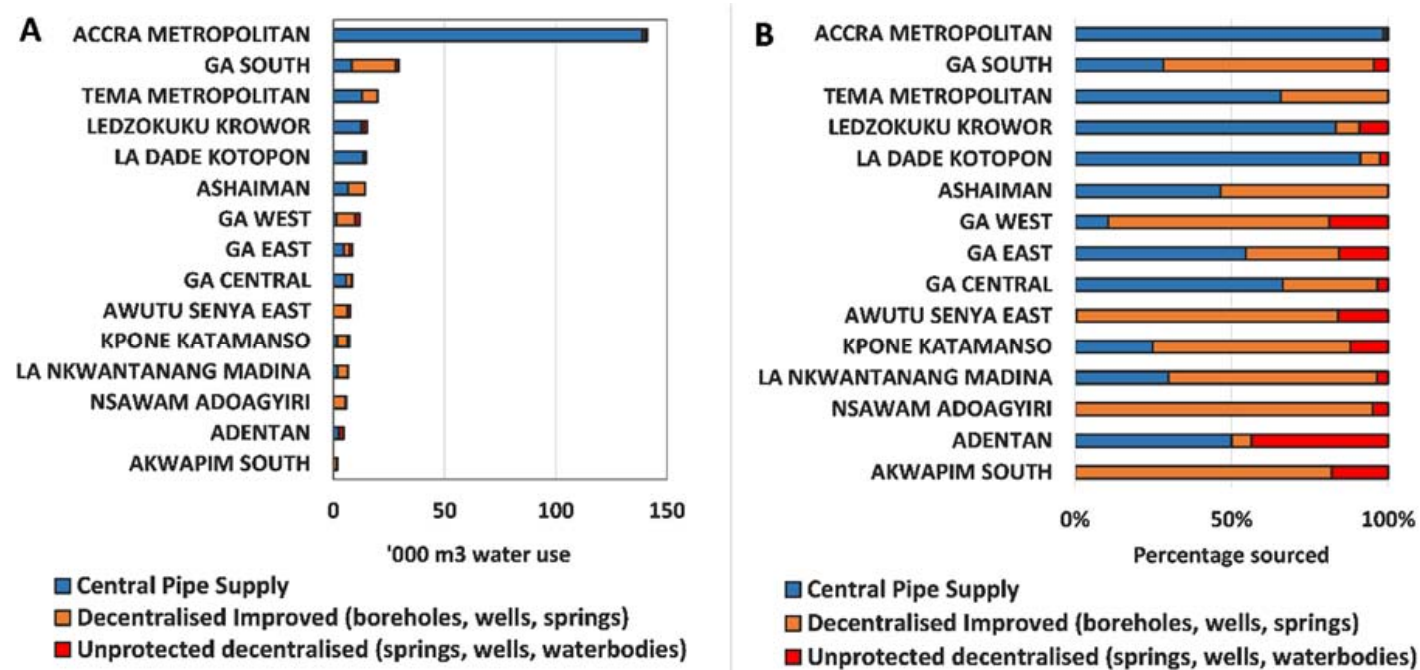

$\square$ Central Pipe Supply

口Decentralised Improved (boreholes, wells, springs)

unprotected decentralised (springs, wells, waterbodies)

Figure 7. Total domestic water use estimate in GAMA per district for 2010 by supply source. (A) Water sourcing in the districts of GAMA by water source type in $\mathrm{m}^{3}$. (B) The water source types for each district as shares of total water use per district.

\subsection{Waste Water and Human Excreta Generation}

The total amount of wastewater generated was estimated at 338 thousand $\mathrm{m}^{3}$ per day in 2010, of which 268 thousand $\mathrm{m}^{3}$ was from the domestic origin. Values for human excreta were estimated at a total amount of $4070 \mathrm{~m}^{3}$ of urine and $1040 \mathrm{~m}^{3}$ of faeces generated per day. An overview of the wastewater, urine, and faeces generated per district is shown below in Figure 8.
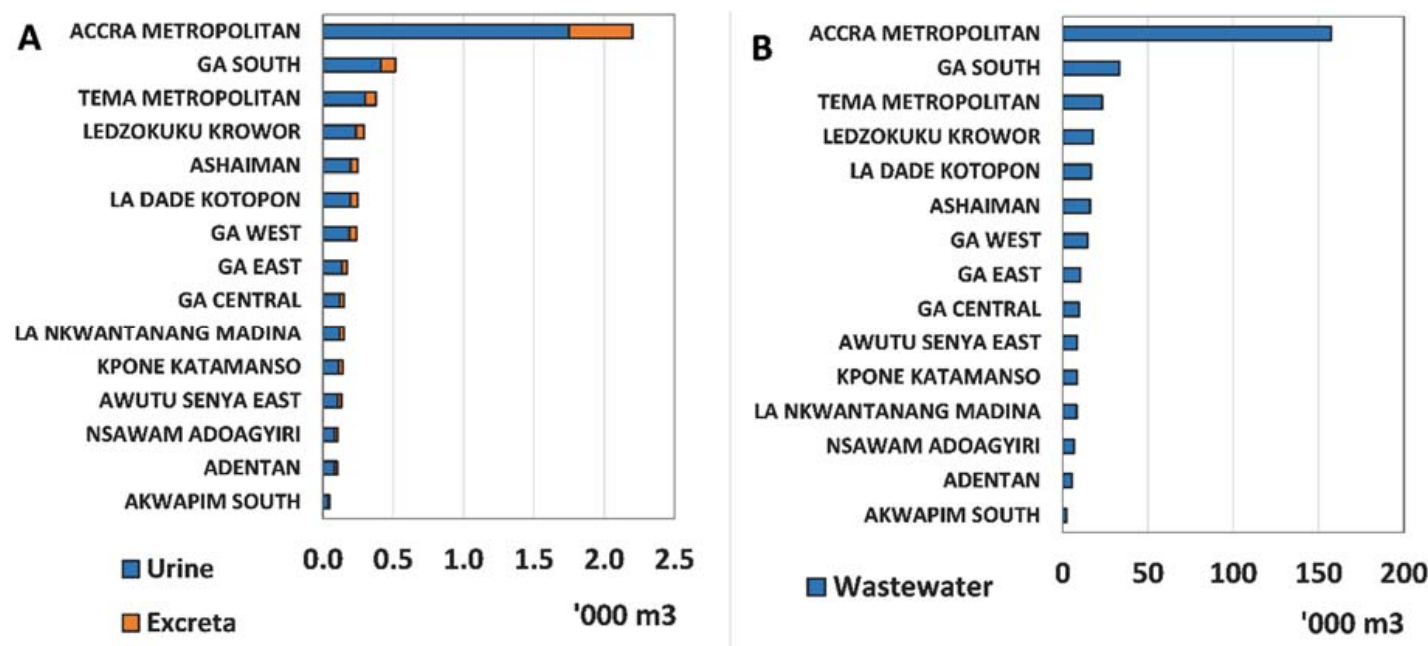

Figure 8. Total wastewater and human excreta (feces and urine) generation estimates in GAMA per district for 2010 by sink. (A) Feces and urine generated per district of GAMA in thousands of $\mathrm{m}^{3}$. (B) Wastewater generated per district of GAMA in thousands of $\mathrm{m}^{3}$. 


\subsection{Wastewater and Sanitation Collection}

The generated wastewater mainly ends up in open-drains connected to local lagoons and the sea, with less than $5 \%$ of households and buildings connected to a sewer system [62]. The two main sewage systems in GAMA are established in the Accra Metropolitan and Tema Metropolitan Districts, with a few minor systems in existence at the site of University of Ghana Legon, hotels and large companies.

On the basis of sewerage figures, an estimated 222 thousand $\mathrm{m}^{3}$ of wastewater generated in 2015 is discharged directly into the environment, 78 thousand $\mathrm{m}^{3}$ into open-drains, and 38 thousand $\mathrm{m}^{3}$ into a sewage pipe network. In terms of sanitation, $91 \%$ of human excreta or $4642 \mathrm{~m}^{3}$ per day is estimated to end up in a variety of toilets systems, and $9 \%$ or $468 \mathrm{~m}^{3}$ per day is directly discharged into the environment via either open defaecation or the use of bucket/pan latrines. However, there is a large variation between districts, as shown in the breakdown of toilet usage for GAMA in Table 4 below [28-42]. Moreover, a large proportion of the population frequents public toilets which are usually 16 or 32 seater types of various make-up (e.g., W.C., improved pit latrines). Total improved toilet access in GAMA was estimated at $81 \%$ with a variation from $54 \%$ to $93 \%$ between districts. Data on public toilets installed is sparse, but generally, the hygienic standards of these toilets are low: in a survey study of four neighbourhoods, it was found that between $17 \%$ and $80 \%$ of public toilets are equipped with handwashing stations, and in $40 \%$ to $88 \%$ of public toilets, faecal matter is visibly present [63].

The numbers of private and public W.C. connected to the sewage systems are a minority. Total excreta entering W.C. is estimated at $1620 \mathrm{~m}^{3}$ per day, of which $478 \mathrm{~m}^{3}$ enters sewage pipes with the majority flowing into septic tanks. The primary collection is thereby carried out via cesspit-tankers, which suck human excreta out of pit latrines and septic tanks. A total estimate of $4165 \mathrm{~m}^{3}$ per day of excreta enters septic tanks and pit latrine systems, out of which $2854 \mathrm{~m}^{3}$ leaks into the sub-soil due to the porous latrine bottom and septic-tank field discharge. The remaining $1298 \mathrm{~m}^{3}$ of excreta is collected via cesspit-emptier services, which, in 2010, were primarily emptied untreated at the 'Lavender Hill' site into the sea. The collected excreta values are similar to reported values by the approximately 125 cesspit-tankers in use in GAMA $[62,64]$. Cesspit-tankers transport human excreta to the disposal site, which can be either treatment facility or the environment (e.g., lagoon or sea). Proportional values for human excreta and wastewater discharge route per district can be found in Figure 9 below.

Table 4. Toilet use proportions in GAMA districts as per the 2010 population census. Source of data: [28-42].

\begin{tabular}{|c|c|c|c|c|c|c|c|c|}
\hline GAMA District & $\begin{array}{c}\text { No } \\
\text { Facilities }\end{array}$ & W.C. & $\begin{array}{c}\text { Pit } \\
\text { Latrine }\end{array}$ & $\begin{array}{c}\text { Kumasi } \\
\text { VIP }\end{array}$ & Bucket/Pan & $\begin{array}{l}\text { Public } \\
\text { Toilet }\end{array}$ & Other & $\begin{array}{c}\text { Improved Toilet } \\
\text { Access }\end{array}$ \\
\hline ACCRA METROPOLITAN & $2.5 \%$ & $33.0 \%$ & $4.3 \%$ & $13.8 \%$ & $4.0 \%$ & $41.9 \%$ & $0.5 \%$ & $88.7 \%$ \\
\hline ADENTAN & $23.5 \%$ & $32.2 \%$ & $12.7 \%$ & $14.7 \%$ & $0.3 \%$ & $16.4 \%$ & $0.2 \%$ & $63.3 \%$ \\
\hline AKWAPIM SOUTH & $8.8 \%$ & $9.5 \%$ & $24.2 \%$ & $15.8 \%$ & $0.7 \%$ & $40.6 \%$ & $0.4 \%$ & $65.9 \%$ \\
\hline ASHAIMAN & $4.0 \%$ & $11.7 \%$ & $2.7 \%$ & $17.5 \%$ & $0.3 \%$ & $63.5 \%$ & $0.3 \%$ & $92.7 \%$ \\
\hline AWUTU SENYA EAST & $15.4 \%$ & $9.2 \%$ & $23.1 \%$ & $11.8 \%$ & $0.5 \%$ & $39.5 \%$ & $0.5 \%$ & $60.5 \%$ \\
\hline GA CENTRAL & $4.9 \%$ & $27.4 \%$ & $40.3 \%$ & $20.8 \%$ & $0.2 \%$ & $6.1 \%$ & $0.4 \%$ & $54.2 \%$ \\
\hline GA EAST & $7.3 \%$ & $42.6 \%$ & $22.7 \%$ & $12.2 \%$ & $0.2 \%$ & $14.3 \%$ & $0.6 \%$ & $69.1 \%$ \\
\hline GA SOUTH & $13.5 \%$ & $26.6 \%$ & $24.0 \%$ & $13.2 \%$ & $0.2 \%$ & $22.0 \%$ & $0.6 \%$ & $61.8 \%$ \\
\hline GA WEST & $6.2 \%$ & $29.7 \%$ & $28.9 \%$ & $22.6 \%$ & $0.1 \%$ & $11.9 \%$ & $0.6 \%$ & $64.2 \%$ \\
\hline KPONE KATAMANSO & $23.9 \%$ & $26.1 \%$ & $7.5 \%$ & $14.4 \%$ & $0.2 \%$ & $27.1 \%$ & $0.8 \%$ & $67.6 \%$ \\
\hline LA DADE KOTOPON & $4.0 \%$ & $42.5 \%$ & $1.5 \%$ & $4.5 \%$ & $2.3 \%$ & $44.4 \%$ & $0.7 \%$ & $91.4 \%$ \\
\hline LA NKWANTANANG MADINA & $6.7 \%$ & $38.8 \%$ & $13.2 \%$ & $23.4 \%$ & $0.1 \%$ & $17.2 \%$ & $0.7 \%$ & $79.4 \%$ \\
\hline LEDZOKUKU KROWOR & $7.8 \%$ & $25.7 \%$ & $5.1 \%$ & $19.1 \%$ & $3.7 \%$ & $38.0 \%$ & $0.6 \%$ & $82.9 \%$ \\
\hline NSAWAM ADOAGYIRI & $3.6 \%$ & $17.7 \%$ & $9.8 \%$ & $17.0 \%$ & $0.7 \%$ & $51.1 \%$ & $0.2 \%$ & $85.8 \%$ \\
\hline TEMA METROPOLITAN & $9.5 \%$ & $53.1 \%$ & $2.1 \%$ & $3.5 \%$ & $0.2 \%$ & $30.8 \%$ & $0.9 \%$ & $87.4 \%$ \\
\hline GAMA & $6.0 \%$ & $32.0 \%$ & $10.0 \%$ & $14.0 \%$ & $2.0 \%$ & $35.0 \%$ & $1.0 \%$ & $80.7 \%$ \\
\hline
\end{tabular}

Table notes: Improved toilet access is the sum of water closet (W.C.), Kumasi VIP, and Public Toilets. W.C. is a flush toilet connected to a sewer or septic tank. 
A

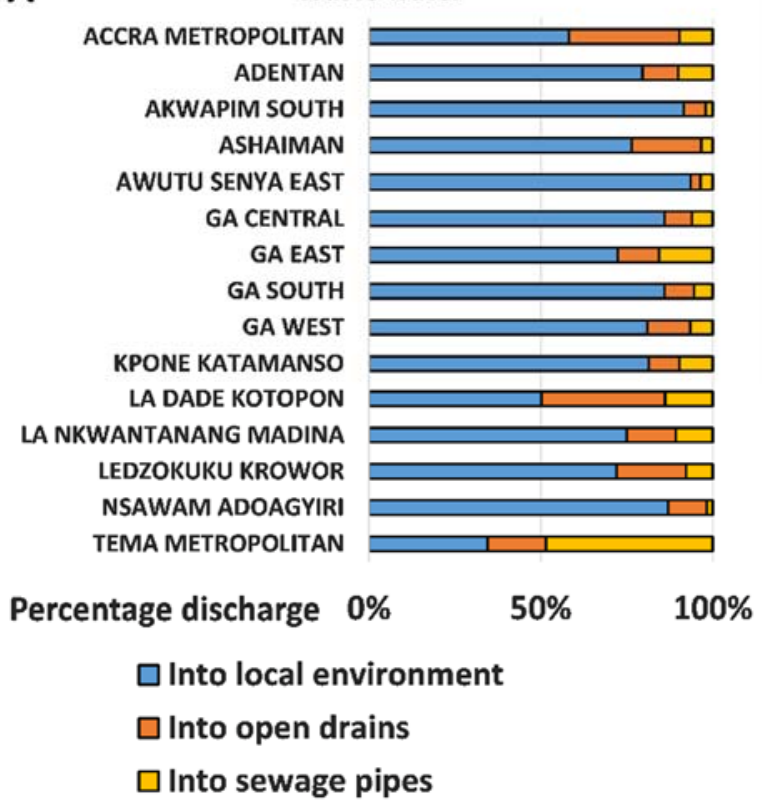

B



Figure 9. Proportion of wastewater and human excreta ending up in the environment and collected via sewage pipes and cesspit-tankers. (A) Share of wastewater per GAMA district discarded into the local environment, open drains or sewage pipes. (B) Share of human excreta (urine and faeces) per GAMA district disposed into the local environment, flown into sewage pipes, collected from septic tanks and pit latrines by tanker trucks, and leaked from septic tanks and pit latrines into the sub-soil.

\subsection{Waste Water Treatment Capacity}

The analysis found that the majority of STPs in GAMA are currently no longer operational due to historic breakdowns, in agreement with previous reports [65]. As a consequence, any sewage routed into the central pipe systems in Acrra Metropolitan Area and Tema Districts is discharged untreated into the sea below the Korle Lagoon and into the Sakumo lagoon, respectively [62]. The total amount of treated liquid waste in 2010 based on treatment capacity, as described below, was negligible at $<0.01 \%$ for wastewater and human excreta. Since then, the situation has improved slightly with, as of 2014 , a total of $0.5 \%$ of wastewater and $8 \%$ of human excreta estimated to have been treated.

In total, four larger public treatment plants have been built since 1997 with a joint capacity of 43 thousand $\mathrm{m}^{3}$, of which two were operational in 2016:

- Slamson Ghana Korle Lagoon cesspit treatment (built in 2013): this polymer separation and drying-based STP with a $400 \mathrm{~m}^{3}$ per day capacity is operational and will be expanded to $1200 \mathrm{~m}^{3}$ per day capacity in the Danish International Development Agency (DANIDA)-funded Lavender Hill Project $[64,66]$;

- Jamestown/Korle Lagoon sewerage plant (built in 2000): this upflow anaerobic sludge blanket (UASB) technology-based STP with a $16,120 \mathrm{~m}^{3}$ per day capacity broke down in 2004 due to a malfunctioning intake pump, potentially caused by inflow of industrial discharge and storm water beyond design specifications [67]. The sewage from the AMA central pipe system is, as a consequence, not treated but directly pumped into the sea at the Korle Lagoon. The plant has been under rehabilitation since 2011, but according to the contractor, work halted in 2013 due to missing payments [68];

- Tema septage central sewer (built in 1997): this aerated lagoon-based STP with seven treatment ponds and a $20,000 \mathrm{~m}^{3}$ per day capacity broke down in 2000 , allegedly due to looting and lack of electricity cables replacement, with degradation now to the point of plant overgrowth in treatment 
basins [69-71]. The sewage from the TEMA central pipe system is in consequence directly pumped into the Sakumo Lagoon;

- University of Ghana Legon Sewerage (built in 2011): this operational waste stabilisation pond-based STP has a $6424 \mathrm{~m}^{3}$ per day capacity, but in 2013/2014, it functioned at only $12 \%$ of design capacity due to limited inflows [62].

The other existing significant larger STPs are mostly privately owned, for example, at the La Palm Royal Beach Hotel, Golden Tulip Hotel, and Nestle Ghana, with a joint service capacity of $750 \mathrm{~m}^{3}$ per day. A small number of smaller plants have also been built, of which a total estimated $112 \mathrm{~m}^{3}$ per day capacity is still operational, as dozens of older smaller plants have significantly degraded or have been removed [26].

\section{Discussion}

The study provides an integrated framework for aiding policymaking, using a bottom-up approach based on material balances. It provides a comprehensive overview of key macro aspects of the WASH system for an urban environment, and to the knowledge of the authors, specifically for the case study of GAMA, it is the first bottom-up analysis based on mass balances, drawing from both literature and locally provided data and information. The WASH material flow methodology as outlined herein is a prerequisite for carrying out scenario analyses, because it provides a sound quantitative basis to rapidly examine the current status of water and sanitation flows, including validation via mass balances to reduce the plausibility of errors. Moreover, this physical flow-based bottom-up analysis combined with accurate WASH sector supply and demand data, provides a robust and unique platform for evaluating future scenarios to improve the urban WASH sector.

The quality of results is reliant on parameter accuracy. Data for the parameter on leakage in the pipe system was found to be limited with only rough estimates of pipe loss values based on the difference between the quantity of water sold and water treated. Additional analyses on physical loss from pipe leakages and improvements in order to reduce non-revenue water would be beneficial, as also indicated by the GWCL. A second area with limited data available was water use in non-domestic sectors, with only indirect estimates available from the GWCL. Data could be generated by carrying out company water use surveys, and by expanding water metering and meter maintenance within GWCL systems.

A large variation was found in parameters for water use per capita by socio-economic variables, income levels, the cost of water, and whether rationing is imposed. The challenge with the range of parameter values is that studies often only include potable water drawn from central pipe systems, and sourcing from other systems is not measured (Banafo, 2013; Lamptey, 2010). The values for rationing are therefore likely biased to lower values, since it can be expected that, when piped supplies are rationed, the population will source water from tankers/vendors or local systems. An exception is the study of [58], but here, only continuous to intermittently well supplied households were analysed. The key aspect of importance that deserves more analysis was found to be the difference between public flat rates and public variable rates, as set by the Public Utilities Regulation Commission (PURC), and private charges for water, which are typically ten to fifteen higher then public rates [72].

The key limitation in the study is the availability of more recent household data than 2010 to provide for a more up-to-date analysis. In particular, figures on household use of non-drinking and drinking water sources, toilets types, and liquid waste discharge were not available. The consequence is that it is difficult to analyse whether improved water and sanitation flows are on track at the level of households per district. A more frequent sub-survey, ideally in line with medium-term development plans of 2014, 2018, and 2022 in GAMA districts, could solve this planning deficit.

Another challenge is the interpretation of key indicators, such as access to improved sources of water, as these depend on definitions, e.g., which sources are included or excluded. In particular, the use of sachet water is key since in the WHO and United Nations (UN) definition it is not to be counted as improved. One reason is that water quality of sachets has been found to vary significantly, with 
occasionally elevated bacterial levels and faecal coliform counts [14]. Notwithstanding, the availability of water sachets in GAMA presents one important improvement in recent times relative to no sachets.

Accra provides a transferable and representative case study because the WASH development level and data availability is similar to other developing countries. Urban planning in many developing countries is limited by the absence of an updated data-driven integrated assessment of urban water flows from raw water to wastewater treatment and discharge. The modelling methodology presented here provides well-defined flow-cycle phases for describing WASH-related flows and performance metrics to accurately characterize WASH flow-cycle. The following eight flow-cycle phases were established in this modelling methodology: (1) central water treatment; (2) potable water distribution; (3) local water sourcing; (4) domestic and non-domestic water use; (5) wastewater generation and toilet use; (6) human excreta production; (7) sewage transport; and (8) sewage treatment. The eight life-cycle phases were established as a standardized set to enable calculations of water and wastewater flows from sourcing to disposal, including sanitation. In comparison to currently available methods, this set of eight WASH flow-cycle phases provides an improved understanding of key data input requirements for WASH planning. These flow-cycle phases can be applied to an entire city or to districts to map potable water treatment, toilets requirements, wastewater treatment, and transport infrastructure needs relative to the current situation. The results can be used to obtain: (1) more accurate midto long-term scenarios for infrastructure requirements, at all levels of governance within the urban environment; and (2) quantification of the costs and benefits of system efficiency improvements, such as pipe loss reductions, versus water treatment expansions.

To highlight the main characteristics described above, the following metrics were applied to describe the WASH map: (1) fresh water use in $\mathrm{m}^{3}$, (2) wastewater generated in $\mathrm{m}^{3}$, (3) urine and excreta generated in $\mathrm{m}^{3}$, (4) proportion of adequately treated sewage in \%. This bottom-up physical modelling methodology, consisting of well-defined flow-cycle phases and performance metrics, promotes the identification of the bottlenecks in WASH flows and WASH planning. In addition, this resource-flow modelling methodology also facilitates scenario testing to overcome these WASH flow and planning bottlenecks with minimal infrastructure material, energy, labour, time and financial investments and with maximal improvements in fresh water supply and wastewater treatment. In this way, optimal and efficient policies, prioritization and investments can be implemented to improve urban WASH sectors.

\section{Conclusions}

A data integration framework and a modelling methodology have been developed for obtaining a baseline understanding of water and sanitation systems in developing countries, where up-to-date district level data is not available. The framework and the model have been applied to GAMA, Ghana. For this application, data has been collected both from documents (e.g., journal articles, local studies and reports) and via personal communications from officials and local WASH service suppliers. The exact data needed was specified by the framework. Once all the data required by the framework was available, descriptive modelling calculations were performed based on the mass balance of water and sanitation flows.

On the basis of the flow data assessment, the WASH landscape has been mapped for GAMA and made available in one place for the first time. In this way, important insights have been gained on centralised raw water treatment, decentralised water sourcing, potable water rationing, improved water use, wastewater and excreta generation, toilet usage, toilet excreta collection, wastewater collection, and wastewater treatment. This framework and the corresponding modelling methodology offer a baseline understanding and open up avenues for improving the WASH sector in developing countries by repeating further data collection efforts guided by the steps and frameworks presented in this paper.

Supplementary Materials: The following are available online at http:/ /www.mdpi.com/2073-4441/10/9/1278/ s1, Supplementary Material A (containing Table S1: Overview of change in GAMA administrative regions 1988-2012); Supplementary Material B (containing Figure S1: Total central water treatment capacity in GAMA in 
$\mathrm{m}^{3}$ from 1980-2015, Figure S2: Total domestic water use estimate in GAMA per district for 2010 by supply source, Figure S3: Total wastewater and human excreta generation estimate in GAMA per district for 2010 by sink, Figure S4: Proportion of wastewater and human excreta ending up in the environment and collected via sewage pipes and cesspit-tankers); Supplementary Material C (containing Table S2: Water consumption in litres per capita per day by income, water sourcing, and rationing from secondary sources plus estimates, Table S3: Proportion of population with central pipe access in rationed areas and with continuous supply and final $\%$ of central water distribution per district, Table S4: Proportion of wastewater discharged onto local soils $\lambda_{\mathrm{q}=1}$, into open drains

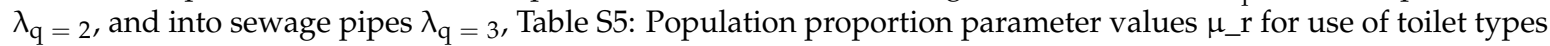
and defaecation practices, Table S6: Toilet use proportions in GAMA districts as per the 2010 population census, Table S7: Parameters established for the material flow analysis.); Supplementary Material D (containing Table S8: Literature overview of studies on human urine excretion, Table S9: Literature overview of studies on human faeces excretion).

Author Contributions: Conceptualization, R.H.E.M.K. and N.S.; methodology, R.H.E.M.K.; validation, F.K.M., R.H.E.M.K., M.N.S. and Z.K.; formal analysis, K.H.v.D., Z.K., X.W., M.N.S., R.H.E.M.K.; investigation, F.K.M., R.H.E.M.K. and Z.K.; resources, N.S.; data curation, K.H.v.D., M.N.S., X.W., C.T., Z.K., R.H.E.M.K.; writing of the original draft preparation, R.H.E.M.K.; writing of review and editing, R.H.E.M.K., X.W., C.T., Z.K., M.N.S., K.H.v.D.; visualization, K.H.v.D., R.H.E.M.K.; supervision, K.H.v.D., R.H.E.M.K. and N.S.; project administration, R.H.E.M.K. and N.S.; funding acquisition, R.H.E.M.K. and N.S.

Funding: The analysis was carried out as part of the UK's Department for International Development (DFID)-funded Future Proofing African Cities for Sustainable Growth project. The authors are grateful to DFID for financial support (grant number 20383).

Conflicts of Interest: The authors declare no conflicts of interest.

\section{References}

1. World Health Organization (WHO); United Nations Children's Fund (UNICEF). Progress on Sanitation and Drinking Water-2015 Update and MDG Assessment; World Health Organization: Geneva, Switzerland, 2015; Available online: https:/ / www.wssinfo.org/fileadmin/user_upload/resources/JMP-Update-report-2015_ English.pdf (accessed on 21 March 2017).

2. World Health Organization (WHO); United Nations Children's Fund (UNICEF). 2015 Annual Report-WHO/UNICEF Joint Monitoring Programme for Water Supply and Sanitation. 2015. Available online: https: / / www.wssinfo.org/fileadmin/user_upload/resources/JMP-2015-Annual-Report-Final.pdf (accessed on 3 April 2017).

3. United Nations. World Population Prospects: Key Findings and Advance Tables, 2015 Revision; Department of Economic and Social Affairs, Population Division: New York City, NY, USA, 2015; Available online: https:/ / esa.un.org/unpd/wpp/Publications/Files/Key_Findings_WPP_2015.pdf (accessed on 3 April 2017).

4. World Health Organization. Preventing Diarrhoea through Better Water, Sanitation and Hygiene-Exposures and Impacts in Low- and Middle-Income Countries; World Health Organization: Geneva, Switzerland, 2014; Available online: http:/ /apps.who.int/iris/bitstream/10665/150112/1/9789241564823_eng.pdf (accessed on 3 April 2017).

5. Hutton, G. Health Impact and Economic Costs of Poor Water and Sanitation. In Encyclopedia of Life Support Systems—Biological, Physiological and Health Sciences; UNESCO: Paris, France, 2010; Available online: http:/ / www.eolss.net/sample-chapters/c03/E2-20A-02-01.pdf (accessed on 6 October 2017).

6. Dos Muchangos, L.S.; Tokai, A.; Hanashima, A. Application of material flow analysis to municipal solid waste in Maputo City, Mozambique. Waste Manag. Res. 2016, 35, 253-266. [CrossRef] [PubMed]

7. Montangero, A. Material Flow Analysis-A Tool to Assess Material Flows for Environmental Sanitation in Developing Countries; Eawag: Dübendorf, Switzerland, 2007; Available online: https://www.eawag. ch/fileadmin/Domain1/Abteilungen/sandec/schwerpunkte/sesp/ESRISS/pdfs/mfa_guidelines.pdf (accessed on 6 October 2017).

8. Twum-Baah, K.A.; Kumekpor, T.K.N.; Addae-Mensah, L.; Appiah, R.; Tawiah, E.O; Wadieh, B. 2000 Population and Housing Census: Greater Accra Region Analysis of District Data and Implications for Planning; Population and Housing Census: Accra, Ghana, 2005.

9. Bentsi-Enchill, N.; Cudjoe, S.N.; Sepah, E.; Anarfi, J.K; Gaisie, S.K. 2010 Population E Housing Census: Regional Analytical Report Greater Accra Region; Population and Housing Census: Accra, Ghana, 2013.

10. GAMA Future Cities Africa Reference Group. Definition of Greater Accra Metropolitan Area. Unpublished work. 2015. 
11. Awuah, E.; Nyarko, K.B.; Owuso, P.A. Water and Sanitation in Ghana. Desalination 2010, 252, 43-50. [CrossRef]

12. Nyarko, K.B. Drinking Water Sector in Ghana: Drivers for Performance; University of Delft: Delft, The Netherlands, 2007.

13. Siita, H.; Mills, J.E.; Musah, I.; Nashiru, A.; Watts, R. Financing of the Water, Sanitation and Hygiene Sector in Ghana; Development Finance International: Washington, DC, USA, 2012.

14. Stoler, J. Spatial Patterns of Water Insecurity in a Developing City: Lessons from Accra, Ghana; University of California Santa Barbara: Santa Barbara, CA, USA, 2012.

15. Abbey, F.M. Assessing Existing Water Demand and Supply Patterns and Reuse Options as Additional Sources of Water in the Greater Accra Metropolitan Area (GAMA); University of Ghana: Accra, Ghana, 2013.

16. Adank, M.; Darteh, B.; Moriarty, P.; Osei-tutu, H.; Van Rooijen, D. Towards Integrated Urban Water Management in the Greater Accra Metropolitan Area; SWITCH/RCN: Accra, Ghana, 2011.

17. Burton, F.; Tchobanoglous, G.; Tsuchihashi, R.; Stensel, H.D. Wastewater Engineering: Treatment and Resource Recovery; Metcalf \& Eddy Inc., Ed.; McGraw-Hill Education: New York, NY, USA, 2013; Available online: https://books.google.co.uk/books/about/Wastewater_Engineering_Treatment_and_Res.html?id= 6KVKMAEACAAJ\&pgis=1 (accessed on 10 February 2018).

18. Water Resources Commission. Water Resources Commission: Water Use Register 2012; Water Resources Commission: Accra, Ghana, 2012.

19. Allotey, J.A.; Anku, S.; Asare, C.; Pwamang, J.; Owusu, M.; Hayfron-Acquah, W. Best Practice Environmental Guidelines Series No. 3: Manual for the Preparation of District Waste Management Plans in Ghana; EPA/MLGRD: Kumasi, Ghana, 2002.

20. Franceys, R.; Pickford, J.; Reed, R.A. Guide to the Development of on-Site Sanitation; WHO: Geneva, Switzerland, 1992; Available online: http://www.who.int/water_sanitation_health/hygiene/envsan/onsitesan.pdf (accessed on 14 February 2018).

21. Foxon, K.; Buckley, C.; Brouckaert, C.; Bakare, B. What Happens When the Pit Is Full ? Water Research Commission: Durban, South Africa, 2011; p. 48.

22. Howard, T.L. Solids Accumulation Rates for Onsite Sewage Treatment and Disposal Systems: a Focus on Charlotte County, Florida. Ph.D. Thesis, University of Florida, Gainesville, FL, USA, 2003. Available online: http:/ / ufdcimages.uflib.ufl.edu/UF/E0/00/26/60/00001/howard_t.pdf (accessed on 11 March 2018).

23. Still, D.A.; Foxon K.M. How Fast Do Pit Toilets Fill Up? A Scientific Understanding of Sludge Build Up and Accumulation in Pit Latrines; Water Research Commission: Gezina, South Africa, 2012.

24. Bounds, T.R. Design and Performance of Septic Tanks; American Society for Testing and Materials: Philadelphia, PA, USA, 1997; pp. 1-21.

25. Heinss, U.; Larmie, S.A.; Strauss, M. Solids Separation and Pond Systems Treatment of Faecal Sludges In the Tropics; EAWAG: Duebendorf, Switzerland, 1998; Available online: https:/ /www.sswm.info/sites/default/files/reference_ attachments/HEINSS1998SolidsSeparationandPondSystemsFortheTreatmentofFaecalSludgesIntheTropics.pdf (accessed on 23 April 2018).

26. TTZ Bremerhaven. Waterbiotech Deliverable D1.3: Report on the General Obstacles Potentially Hindering Any Innovative Biotechnological Wastewater Treatments Implementation in the Targeted Countries; TTZ Bremerhaven: Bremerhaven, Germany, 2012.

27. Government of Ghana. Local Government Act 1993; Government of Ghana: Accra, Ghana, 1993.

28. Ghana Statistical Service. 2010 Population $\mathcal{E}$ Housing Census: Awutu Senya East Municipality District Analytical Report; Ghana Statistical Service: Accra, Ghana, 2014.

29. Ghana Statistical Service. 2010 Population \& Housing Census: Nsawam-Adoagyiri Municipality District Analytical Report; Ghana Statistical Service: Accra, Ghana, 2014.

30. Ghana Statistical Service. 2010 Population E Housing Census: Ga West Municipality District Analytical Report; Ghana Statistical Service: Accra, Ghana, 2014.

31. Ghana Statistical Service. 2010 Population E Housing Census: Adentan Municipality District Analytical Report; Ghana Statistical Service: Accra, Ghana, 2014.

32. Ghana Statistical Service. 2010 Population $\mathcal{E}$ Housing Census: Ga East Municipality District Analytical Report; Ghana Statistical Service: Accra, Ghana, 2014.

33. Ghana Statistical Service. 2010 Population E Housing Census: Ashaiman Municipality District Analytical Report; Ghana Statistical Service: Accra, Ghana, 2014. 
34. Ghana Statistical Service. 2010 Population E Housing Census: La Nkwantanang-Madina Municipality District Analytical Report; Ghana Statistical Service: Accra, Ghana, 2014.

35. Ghana Statistical Service. 2010 Population \& Housing Census: Akwapim South District District Analytical Report; Ghana Statistical Service: Accra, Ghana, 2014.

36. Ghana Statistical Service. 2010 Population E Housing Census: Accra Metropolitan District Analytical Report; Ghana Statistical Service: Accra, Ghana, 2014.

37. Ghana Statistical Service. 2010 Population \& Housing Census: Kpone-Katamanso District District Analytical Report; Ghana Statistical Service: Accra, Ghana, 2014.

38. Ghana Statistical Service. 2010 Population E Housing Census: Ga Central Municipality District Analytical Report; Ghana Statistical Service: Accra, Ghana, 2014.

39. Ghana Statistical Service. 2010 Population E Housing Census: Ga South Municipality District Analytical Report; Ghana Statistical Service: Accra, Ghana, 2014.

40. Ghana Statistical Service. 2010 Population E Housing Census: La Dade-Kotopon Municipality District Analytical Report; Ghana Statistical Service: Accra, Ghana, 2014.

41. Ghana Statistical Service. 2010 Population E Housing Census: Ledzokuku-Krowor Municipality District Analytical Report; Ghana Statistical Service: Accra, Ghana, 2014.

42. Ghana Statistical Service. 2010 Population E Housing Census: Tema Metropolitan District Analytical Report; Ghana Statistical Service: Accra, Ghana, 2014.

43. QGIS Development Team. QGIS Geographic Information System. Open Source Geospatial Foundation Project. 2018. Available online: https:/ / qgis.org/en/site/ (accessed on 17 June 2017).

44. Al-Hassan, K.Y. Water Demand Management of Domestic Water in the Accra, Tema Metropolitan Area (ATMA). Ph.D. Thesis, Unesco-IHE, Delft, The Netherlands, 2007.

45. Van Rooijen, D.J. Implications of Urban Development for Water Demand, Wastewater Generation and Reuse in Water-Stressed Cities: Case studies from South Asia and Sub-Saharan Africa. Ph.D. Thesis, Lougborough University, Loughborough, UK, 2011.

46. Uusitalo, K. An Evaluation of Urban Water Systems Using Environmental Sustainability Indicators: A Case Study in Adenta, Ghana; Chalmers University of Technology: Göteborg, Sweden, 2002.

47. Ghana Districts. Weija: Weija Treatment Plant Project Completed; Ghana Districts: Accra, Ghana, 2008.

48. Water-Technology. net. Adam Clark Water Treatment Plant; Water-Technology: Weija, Ghana, 2014.

49. GNA. Weija Plant to Produce at Capacity; GNA: Accra, Ghana, 2013.

50. Andoh, D. Expansion Works on Kpong Water Plant Almost Completed; KWSEP: Kuala Lumpur, Malaysia, 2014.

51. Tahal Group. A World of Sustainable Development; Tahal Group: Amsterdam, The Netherlands, 2011; p. 39.

52. AidData. China Gives Ghana 273 m Dollars for Expansion of Water Supply Project; AidData: Washington, DC, USA, 2010.

53. GNA. GWCL Produces Enough Water at Kpong. 2015. Available online: http://www.ghananewsagency. org/print/90118 (accessed on 22 July 2017).

54. Water-Technology.net. Accra Sea Water Desalination Plant; Water-Technology: Weija, Ghana, 2015; pp. 3-5.

55. Lamptey, F. Determination of Domestic Water Consumption Pattern in Accra. Ph.D. Thesis, Kwame Nkrumah University of Science and Technology, Kumasi, Ghana, 2010.

56. World Bank Group; Cowater International; WSUP U.K.; WASHealth Solutions. Final Report on Field Assessment of Selected LIUCs; World Bank Group: Washington, DC, USA, 2013.

57. Banafo, K.S. Water Consumption and Its Variations in Koforidua. Ph.D. Thesis, Kwame Nkrumah University of Science and Technology, Kumasi, Ghana, 2013.

58. Abraham, E.M. Planning Urban Water-Dependent Livelihood Opportunities for the Poor in Accra, Ghana; University of Greenwich: London, UK, 2011.

59. Allen, M.; Clark, R.; Cotruvo, J.A.; Grigg, N. Drinking Water and Public Health in an Era of Aging Distribution Infrastructure; Public Work Manag Policy; SAGE Publications Inc.: Thousand Oaks, CA, USA, 2018.

60. Pieper, K.J.; Tang, M.; Edwards, M.A. Flint Water Crisis Caused By Interrupted Corrosion Control: Investigating “Ground Zero" Home. Environ. Sci. Technol. 2017, 51, 2007-2014. [CrossRef] [PubMed]

61. Liu, J.; Chen, H.; Yao, L.; Wei, Z.; Lou, L.; Shan, Y. The spatial distribution of pollutants in pipe-scale of large-diameter pipelines in a drinking water distribution system. J. Hazard. Mater. 2016, 317, 27-35. [CrossRef] [PubMed] 
62. Hydrophil, I.C. Report on the Financial Viability of Faecal Sludge End-Use in Dakar, Kampala and Accra; ResearchGate: Vienna, Austria, 2014.

63. Peprah, D.; Baker, K.K.; Moe, C.; Robb, K.; Wellington, N.; Yakubu, H.; Null, C. Public toilets and their customers in low-income Accra, Ghana. Environ. Urban. 2015, 27, 589-604. [CrossRef]

64. Fournais, P.A.; Elkjaer, M. The Sludge Treatment Project at "Lavender Hill", Accra Ghana; Internal Grant Committee, Danish Ministry of Foreign Affairs, Danish Ministry of Foreign Affairs: Copenhagen, Denmark, 2015.

65. Murray, A.; Drechsel, P.A.Y. Why do some wastewater treatment facilities work when the majority fail? Case study from the sanitation sector in Ghana. Waterlines 2011, 30, 1-15. [CrossRef]

66. Nikiema, J.; Cofie, O.; Impraim, R. Resource Recovery and Reuse Series 2: Technological Options for Safe Resource Recovery from Fecal Sludge; Resource Recovery and Reuse: Colombo, Sri Lanka, 2014.

67. Isabella, L. Analysis of the Public Health Risks of the Urban Water System in Accra by Microbial Risk Assessment; Unesco-IHE: Delft, The Netherlands, 2007.

68. Channel Two Communications. The Shame of Lavender Hill; Channel Two Communications: Oxford, UK, 2014; Available online: http:/ / channeltwoportal.com/sewage-the-shame-of-lavender-hill/ (accessed on 27 July 2017).

69. Antwi-Agyei, P. Faecal Sludge Managemen the Case of Madina. Master's Thesis, Kwame Nkruma University of Science and Technology, Madina, Saudi Arabia, 2009. Available online: http:/ /ir.knust.edu.gh/xmlui/ handle/123456789/823 (accessed on 25 July 2017).

70. Bediako, J. TEMA Is Broke Can't Provide Just GHC500 to Repair Treatment Plant; The Chronicle: San Francisco, CA, USA, 2015; Available online: https: / / allafrica.com/stories/201507281132.html (accessed on 25 July 2017).

71. Daily Graphic. TEMA Sewage Treatment Plsant Left to Rot. Broke down 12 Years Ago. Daily Graphic. 14 November 2012. Available online: https://www.ghanaweb.com/GhanaHomePage/regional/Temasewage-treatment-plant-left-to-rot-Broke-down-12-years-ago-256310 (accessed on 24 July 2017).

72. Peloso, M.; Morinville, C. "Chasing for water": Everyday practices of water access in Peri-Urban Ashaiman, Ghana. Water Altern. 2014, 7, 121-139. 